\title{
Assessing remote polarimetric measurement sensitivities to aerosol emissions using the geos-chem adjoint model
}

\author{
B. S. Meland ${ }^{1}$, X. Xu ${ }^{2}$, D. K. Henze ${ }^{1}$, and J. Wang ${ }^{2}$ \\ ${ }^{1}$ University of Colorado - Boulder, Mechanical Engineering Dept., Boulder, CO 80309, USA \\ ${ }^{2}$ University of Nebraska - Lincoln, Dept. of Earth and Atmospheric Sciences, Lincoln, NE 68588, USA
}

Correspondence to: B. S. Meland (brian.meland@du.edu)

Received: 5 April 2013 - Published in Atmos. Meas. Tech. Discuss.: 19 June 2013

Revised: 5 November 2013 - Accepted: 6 November 2013 - Published: 10 December 2013

\begin{abstract}
Uncertainties in aerosol sources, microphysical properties, and global distributions undermine efforts to evaluate the radiative impacts of atmospheric aerosols. In this work, we investigate the feasibility of using remote polarimetric measurements for constraining aerosol and aerosol precursor emissions in light of these uncertainties. A model that incorporates a radiative transfer model with forward and adjoint chemical transport models has been applied to quantify the sensitivity of the reflectance at the top of atmosphere over land to aerosol emissions and microphysical properties. A set of simulated satellite observations, one intensity based and one capable of polarimetric measurements, are used to illustrate differences in the assimilation potential between the two. It is found that the sensitivity of the polarized reflectance to aerosol and aerosol precursor emissions tends to be significantly higher than that of the intensity for cases of non-absorbing aerosols. This is true even when the polarimetric sampling scheme is spatially sparser than that of the intensity sampling. This framework allows us to quantify upper limits on the uncertainties in the aerosol microphysical properties for which a $50 \%$ change in aerosol emissions is detectable using these simulated observations. It was found that although typical current remote sensing instrumentation provides retrievals of the refractive index and effective radius with accuracies within acceptable limits to detect a $50 \%$ change in emissions, retrievals of the effective variance contain uncertainties too large to detect these changes in emissions. These results may guide new applications of polarimetric measurements to constrain aerosol sources, and thus reduce uncertainty in our broader understanding of the impacts of aerosols on climate.
\end{abstract}

\section{Introduction}

Aerosols play a significant role in Earth's atmosphere by affecting the planet's radiative balance, cloud properties, and heterogeneous chemistry. Depending on the composition and the three-dimensional spatial distribution of the aerosol, incident solar radiation may be scattered or absorbed, resulting in positive or negative direct radiative forcing. Indirect aerosol effects include changes in microphysical properties and lifetimes of clouds by serving as cloud condensation nuclei, and radiative absorption due to aerosols can also alter the ambient cloud cover via the semi-direct aerosol effect (Hansen et al., 1997). Unfortunately, our understanding of the net radiative effects of atmospheric aerosol is limited by uncertainties in our knowledge of the global distribution, composition, and sources of atmospheric aerosol (Kinne et al., 2006; Schulz et al., 2006; Forster et al., 2007; Myhre et al., 2013; Stier et al., 2013).

In situ and remote sensing measurements provide a means of reducing uncertainty in our understanding of aerosol radiative forcing. Multiple observation networks and platforms provide a range of constraints on aerosol distributions and microphysical properties. Aerosol concentrations are measured from both ground-based, such as the AErosol RObotic NETwork (AERONET; Holben et al., 1998), and satellite based detectors (King et al., 1999), including the Moderate-resolution Imaging Spectroradiometer (MODIS; Salomonson et al., 1989), Polarization and Directionality of the Earth's Reflectances (POLDER; Deschamps et al., 1994), Multi-angle Imaging SpectroRadiometer (MISR; Diner et al., 1998), or the Aerosol Polarimetry Sensor (APS; Peralta et al., 2007). Depending on the mission goals for each platform, 
measurements may include only intensity observations, as is the case for the MODIS and MISR instruments, or may include polarimetric data as well, for example the POLDER or APS instruments. Retrieval algorithms are used to deduce the aerosol optical depth and size distribution information from the measured signal (e.g., Remer et al., 2005; Dubovik et al., 2011). These retrievals rely on a priori assumptions of aerosol optical properties, size distributions, and shape, which may differ between retrieval algorithms. For instance, the POLDER retrieval assumes spherical aerosol particles in its inversion (Deuze et al., 2000) whereas the AERONET sky retrieval algorithm assumes either spherical (Dubovik and King, 2000) or spheroidal (Dubovik et al., 2002) particles depending on the particle size. These different assumptions may lead to discrepancies between retrieved quantities and inferences made from these regarding aerosol distributions and sources.

The accuracy of remote retrieval of aerosol properties can be enhanced by utilizing measurements of the full polarimetric state of light as well as spectral measurements (Chowdhary et al., 2005). Kokhanovsky et al. (2010) compared the capability of a number of retrieval algorithms (MODIS, MISR, AATSR, and POLDER algorithms) for determining aerosol optical depth and microphysical properties from a simulated data set. It was found that multi-angle, multi-wavelength, polarimetric retrievals outperformed those that only used scattered light intensity or measurements from a single viewing angle. Knobelspiesse et al. (2012) simulated the instrument measurement characteristics of MISR, POLDER, and the Aerosol Polarimetry Sensor (APS) in order to quantify the information content of each measurement technique and to determine the sensitivity of each set of measurements to aerosol properties. It was again found that multi-angle, spectral, polarimetric measurements were most capable of accurate aerosol retrieval.

Atmospheric chemistry and transport models, which simulate the production, loss, interaction, and transport of numerous chemical species and aerosols, provide a means of estimating the role of specific processes in determining the overall radiative impacts of aerosols. Comparisons across models have been used to identify the contribution to the total uncertainty owing to treatment of emissions (Textor et al., 2006), surface albedo and cloud distributions (Stier et al., 2007, 2013), and aerosol optical properties and radiative transfer (Kinne et al., 2006; Myhre et al., 2013). To reduce our uncertainty in the sources and distribution of aerosols, observations and models can be combined through data assimilation. For example, aerosol optical depth has been assimilated operationally to improve meteorological forecasts (Zhang et al., 2008; Benedetti et al., 2009), and radiances have been used to constrain emissions of aerosols and aerosol precursors (e.g., Dubovik et al., 2008; Wang et al., 2012).

While these previous works focused on constraining aerosol properties using polarimetric remote sensing measurements, or aerosol sources using intensity measurements, there has been less consideration of the value of polarimetric measurements for deriving constraints on aerosol and aerosol precursor concentrations or emissions. The goal of this work is to quantify the utility of polarimetric measurements versus intensity based measurements for inferring aerosol microphysical properties and as a possible means of constraining aerosol emissions through use of a simulated set of remote satellite measurements. We consider two sets of simulated remote sensing observations, both derived from a flight path closely aligned with that of two former satellites capable of polarimetric measurements: PARASOL (part of the A-train between 2004 and 2009) (Fougnie et al., 2007) and that of the failed Glory satellite (Mishchenko et al., 2007). The simulated observations of the TOA reflectances were constrained to be located over N. America and were thus all over land. All simulated observations and radiative transfer calculations were made at a wavelength of $650 \mathrm{~nm}$. One simulated satellite, based on specifications of the MODIS instrument aboard the Aqua satellite, is constrained to intensity measurements, while a second simulated satellite is assumed to be capable of polarimetric measurements. Though typical satellite instruments capable of polarimetric measurements (i.e., POLDER or APS) include multi-angle measurement capabilities, to highlight differences in the sensitivities due to intrinsic differences in the intensity-based and polarized reflectance, the viewing zenith angle is constrained to zero degrees for both the radiant and polarized reflectance calculations. This may not be an unrealistic constraint on these calculations as there is currently a polarimetric sensor that is only able to measure the polarized reflectance from a single viewing angle, the Global Ozone Monitoring Experiment (GOME-2) instrument on board the MetOp-A and MetOp-B satellites (Callies et al., 2000). We have explored changes to the sensitivities resulting from the implementation of multiple viewing angles in the polarimetric simulated satellite, though do not present a rigorous treatment of that case in this work.

The single particle light scattering properties of the aerosols were calculated using the Mie theory and assume spherical particles. The sensitivities of the top of atmosphere (TOA) Stokes parameters, from which the reflectances are derived, to aerosol concentrations and microphysical properties are calculated using the Vector LInearized Discrete Ordinate Radiative Transfer (VLIDORT) model (Spurr, 2006) over the simulated satellite flight path. These results are used as inputs to an adjoint model of the CTM to propagate sensitivities back to aerosol emissions. The overall modeling framework is described in Sect. 2, with additional background on the derivation of the sensitivity equations provided as an Appendix. Section 3 contains specific model configurations used in these calculations as well as details of the simulated satellite observations. Results are included in Sect. 4, followed by discussion and conclusions in Sect. 5 . 


\section{Theory}

Determination of the sensitivity of the TOA reflectance to atmospheric aerosol properties and emissions is performed using a coupling of the GEOS-Chem forward and adjoint chemical transport models (Bey et al., 2001; Henze et al., 2007), a vectorized linear radiative transfer model, VLIDORT (Spurr, 2006), modified to incorporate MODIS data from the Aqua satellite, MARIA (MODIS AOD Retrieval by an Improved Algorithm) (Wang et al., 2010), and a linearized Mie light scattering algorithm (Spurr et al., 2012). A flow chart of the model components and their inputs and outputs is shown in Fig. 1. In that diagram, the red boxes correspond to external model inputs such as meteorological parameters, surface reflectances, and satellite position. Blue boxes correspond to the model calculations, and green boxes represent model outputs.

Here we describe the basic structure and relevant inputs to the models used to calculate the sensitivities of TOA reflectance. The GEOS-Chem CTM is described in Sect. 2.1. In Sect. 2.2, the radiative transfer model and the methods for the calculation of the sensitivity of the TOA Stokes parameters to aerosol concentration and microphysical parameters are described. The adjoint of the GEOS-Chem model is detailed in Sect. 2.3 along with methods for determining the sensitivity of the Stokes parameters to emissions. From the Stokes sensitivities, we calculate the sensitivities of the radiant reflectance and polarized reflectance to aerosol loading, emissions, and microphysical properties.

\subsection{GEOS-chem}

Atmospheric aerosol concentrations are calculated using the GEOS-Chem global three-dimensional chemical transport model (Bey et al., 2001) driven by GEOS-5 meteorological reanalysis fields from the Global Modeling and Assimilation Office (GMAO), degraded to $4^{\circ} \times 5^{\circ}$ horizontal resolution on a 47 layer vertical grid extending up to $0.01 \mathrm{hPa}$. The transport time step is $30 \mathrm{~min}$ and aerosol concentrations are calculated for each hour of the simulations. Model simulations include gas-phase $\mathrm{NO}_{\mathrm{x}}-\mathrm{O}_{\mathrm{x}}-\mathrm{VOC}$ photochemistry (Bey et al., 2001) coupled with formation of sulfate, nitrate, ammonium, and carbonaceous aerosols, which are determined on a global scale using methods developed by Park et al. (2003, 2004). Simulations of mineral dust and sea salt aerosols are based on the works of Fairlie et al. (2007) and Alexander et al. (2005) respectively. Dry deposition is calculated using a resistance in series approach (Wesely, 1989; Wang et al., 1998) and wet deposition and scavenging of aerosols and trace gases are accounted for (Liu et al., 2001; Mari et al., 2000).

Emissions are taken from the following inventories. Global anthropogenic emissions of $\mathrm{NO}_{\mathrm{x}}, \mathrm{CO}$, and $\mathrm{SO}_{\mathrm{x}}$ are obtained from the Emissions Database for Global Atmospheric Research (EDGAR; Olivier and Berdowski, 2001), which is overwritten by regional emissions as follows: EMEP

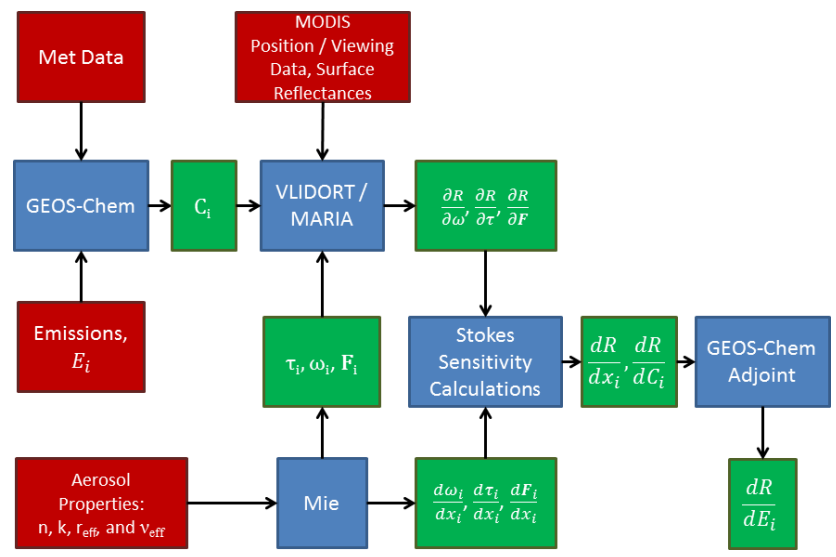

Fig. 1. Flow chart of the chemical transport, radiative transfer, and adjoint models used in this work. Red boxes correspond to external model inputs, blue to the model itself, and green for model results.

inventories are used over Europe, BRAVO over Mexico, Street et al. (2006) over S.E. Asia, CAC over Canada, NEI 2005 over the United States, and global emissions of carbonaceous aerosols are from Bond et al. (2007). Biofuel emission inventories are obtained from Yevich and Logan (2003). Contributions from biomass burning are taken from GFED v2 (van der Werf et al., 2006). Emissions of biogenics are taken from MEGAN v1.2 (Guenther et al., 2006). $\mathrm{NO}_{\mathrm{x}}$ emissions from lighting are determined using the algorithm of Price and Rind (1992).

\subsection{Radiative transfer algorithm}

The Stokes vector, $\boldsymbol{S}$, completely describes the polarization state of electromagnetic radiation. The Stokes vector of scattered light at TOA depends upon the bulk optical properties of the atmosphere it passes through. These properties include the extinction optical depth, $\tau$, the single scattering albedo, $\omega$, the scattering matrix, $\boldsymbol{F}$, as well as the scattering geometry (viewing angle and solar angle, relative azimuth angle). These bulk properties in turn depend upon the optical properties $\left(\tau_{i}, \omega_{i}, \boldsymbol{F}_{i}\right)$ of the individual aerosol and molecular species present in the atmospheric column through which the light passes. The species specific optical properties are further dependent on the aerosol concentrations and microphysical properties (Bohren and Huffman, 1983).

A total of seven aerosol species are considered in the radiative transfer calculations including organic and black carbon (hydrophilic and hydrophobic), sulfate, nitrate, and ammonium. Aerosols are approximated as spherical and the Mie theory is used to calculate their optical properties assuming the aerosols are externally mixed. Inputs to the Mie algorithm include the complex refractive index, $n+i k$, and the aerosol size distribution. The size distribution is parameterized in this model by assuming a log-normal distribution defined by the effective radius, $r_{\text {eff }}$, and the effective variance of 
the size distribution, $v_{\text {eff }}$. These Mie calculations are repeated for seven different values of the relative humidity, $\mathrm{RH}(0,50$, $70,80,90,95$, and $99 \%$ ). The aerosol properties, refractive index and size parameters, are adjusted to account for water uptake on the surface of the particles for each RH value. These RH dependent aerosol parameters are taken from the Global Aerosol Data Set (GADS) (Martin et al., 2003). A complete list of these input parameters used in these calculations for all aerosol species is included in Table 1. For the cases of hydrophilic aerosols, these parameters are shown for $70 \% \mathrm{RH}$. The Mie code used here is linearized and is able to numerically calculate the derivatives (Jacobians) of the optical properties with respect to the aerosol property inputs. The optical properties (and their corresponding derivatives) calculated by the Mie code include the single scattering albedo, the extinction optical depth, and the scattering matrix for each aerosol species. All optical properties were calculated assuming a wavelength of $650 \mathrm{~nm}$.

The single scattering optical properties from the Mie code and the aerosol concentrations from the GEOS-Chem model are used as inputs to the radiative transfer model, MARIA (MODIS AOD Retrieval by an Improved Algorithm; Wang et al., 2010), which is an adaptation of the VLIDORT model (Spurr, 2006, 2008). The aerosol contribution to the extinction optical depth, single scattering albedo, and scattering matrix expansion coefficients are determined for each atmospheric layer using the optical properties for each aerosol species generated using the Mie theory using methods discussed in the Appendix (Eqs. A6-A8).

Molecular light scattering is calculated using applications of Rayleigh scattering theory as implemented by Bodhaine et al. (1999). Refractive indices, depolarization ratios, and light scattering cross sections of air are first calculated using estimates of the relative composition of dry air. From these, gaseous contributions to the extinction optical depth, single scattering albedo, and scattering matrix are estimated. A total of 20 atmospheric layers are used in these calculations in order to significantly reduce the computational requirements of the radiative transfer calculations. Aerosol concentrations from the GEOS-Chem model were interpolated onto this 20 layer grid from the 47 layer native grid prior to being used in the calculations. The VLIDORT model uses these values to calculate the full Stokes vector at the TOA. Though the full Stokes vector is calculated, we neglect any contributions from circularly polarized light in our calculations of the polarized reflectance. This contribution tends to be negligible and is typically not measured by remote polarimetric sensors (Fougnie et al., 2007; Mishchenko et al., 2007).

MODIS data used in this model are obtained from the Level 1 and Atmosphere Archive and Distribution System (LAADS) of the NASA Goddard Space Flight Center. Level 2 aerosol data from the Aqua satellite was restricted to that over the same time period of the GEOS-Chem simulation and to the North American region. Parameters used from the MODIS data include the viewing geometry of the satellite (viewing angle, solar position relative to the viewing angle, and geolocation) as well as surface reflectivities for the $646 \mathrm{~nm}$ wavelength channel. The surface reflectances from MODIS are used to constrain the amplitude of the surface reflectance and a bidirectional reflectance distribution function, BRDF, is calculated by a VLIDORT subroutine in order to account for surface geometry effects (shading, viewing angle, etc.). The surface reflectivities used in the radiative transfer calculations are shown in Fig. 2. These values have been averaged over the over the two weeks of the model run. For this figure, the reflectivities have been degraded to $4^{\circ} \times 5^{\circ}$ horizontal resolution for comparison with the adjoint sensitivities discussed in Sect. 2.3. In this work, the zenith angle was constrained to zero degrees for both the intensity and polarimetric calculations of the reflectances. A brief discussion of the effects of including multiple viewing angles in these sensitivity studies is included in Sect. 5. Calculations of the TOA reflectances were performed on a pixelby-pixel basis. Since the MODIS data files each contain a large amount of pixels (> 25000$)$, it was necessary for computational tractability to sub-sample the MODIS grid prior to these calculations.

\subsection{Sensitivity calculations}

The derivatives of the TOA Stokes parameters with respect to the atmospheric optical properties (i.e., $\frac{\partial \mathbf{S}}{\partial \omega} \frac{\partial \mathbf{S}}{\partial \tau}$, and $\frac{\partial \mathbf{S}}{\partial \mathbf{F}}$ ) are calculated in the radiative transfer model at each atmospheric layer using a Taylor series expansion of the radiation field, keeping only the first term in the expansion (Spurr, 2006). For this work, we examined the sensitivities of both the radiant reflectance, $R_{I}$, as well as the polarized reflectance, $R_{\mathrm{p}}$. These quantities are defined in terms of the Stokes parameters in the Appendix (Eqs. A3, A4). It should be reiterated here that contributions from the circularly polarized component of $\mathbf{S}$ are not used in the calculation of the polarized reflectance. $R_{\mathrm{p}}$ only contains the contributions from linearly polarized light. In the following derivations, we will use $R$ to mean either the radiant or the polarized reflectance in cases where equivalent expressions exist for each. The derivatives of the Stokes parameters are used to calculate the derivatives of the reflectances $\left(\frac{\partial R}{\partial \omega} \frac{\partial R}{\partial \tau}\right.$, and $\left.\frac{\partial R}{\partial \mathbf{F}}\right)$. These values are then used, along with the derivatives determined in the Mie code $\left(\frac{\mathrm{d} \omega_{i}}{\mathrm{~d} x_{i}}, \frac{\mathrm{d} \tau_{i}}{\mathrm{~d} x_{i}}\right.$, and $\left.\frac{\mathrm{d} \mathbf{F}_{i}}{\mathrm{~d} x_{i}}\right)$, to generate the sensitivities of the TOA reflectance with respect to the aerosol concentrations, Eq. (1), or microphysical properties, Eq. (2), of each aerosol species in each atmospheric layer:

$$
\begin{aligned}
& \frac{\mathrm{d} R}{\mathrm{~d} C_{i}}=\frac{\partial R}{\partial \omega} \frac{\mathrm{d} \omega}{\mathrm{d} C_{i}}+\frac{\partial R}{\partial \tau} \frac{\mathrm{d} \tau}{\mathrm{d} C_{i}}+\frac{\partial R}{\partial \mathbf{F}} \frac{\mathrm{d} \mathbf{F}}{\mathrm{d} C_{i}}, \\
& \frac{\mathrm{d} R}{\mathrm{~d} x_{i}}=\frac{\partial R}{\partial \omega} \frac{\partial \omega}{\partial \omega_{i}} \frac{\mathrm{d} \omega_{i}}{\mathrm{~d} x_{i}}+\frac{\partial R}{\partial \tau} \frac{\partial \tau}{\partial \tau_{i}} \frac{\mathrm{d} \tau_{i}}{\mathrm{~d} x_{i}}+\frac{\partial R}{\partial \mathbf{F}} \frac{\partial \mathbf{F}}{\partial \mathbf{F}_{i}} \frac{\mathrm{d} \mathbf{F}_{i}}{\mathrm{~d} x_{i}},
\end{aligned}
$$

where $x_{i}$ represents any of $n_{i}, k_{i}, r_{\mathrm{eff}, i}$, and $v_{\mathrm{eff}, i}$ and the subscript $i$ is the aerosol species. Evaluation of the terms on 
Table 1. Aerosol microphysical properties used in the Mie calculation of aerosol properties. Values are given for the complex refractive index, $m$, and the effective radius and variance, $r_{\text {eff }}$ and $v_{\text {eff }}$, of the aerosol size distribution assuming a log-normal distribution. Values are taken from the Global Aerosol Data Set described in Koepke et al. (1997). For the case of hydrophilic aerosols, values are only shown for $70 \% \mathrm{RH}$.

\begin{tabular}{llrrr}
\hline Name & Description & $m=n+i k$ & $r_{\text {eff }}(\mu \mathrm{m})$ & $\nu_{\text {eff }}$ \\
\hline $\mathrm{SO}_{4}$ & Sulfate & $1.36+0.00 i$ & 0.213 & 0.25 \\
$\mathrm{NH}_{4}$ & Ammonium & $1.36+0.00 i$ & 0.213 & 0.25 \\
$\mathrm{NIT}$ & Inorganic sulfur nitrates & $1.36+0.00 i$ & 0.213 & 0.25 \\
$\mathrm{BCPI}$ & Black carbon (hydrophilic) & $1.75+0.44 i$ & 0.039 & 0.25 \\
$\mathrm{OCPI}$ & Organic carbon (hydrophilic) & $1.41+0.00 i$ & 0.171 & 0.25 \\
$\mathrm{BCPO}$ & Black carbon (hydrophobic) & $1.75+0.44 i$ & 0.039 & 0.25 \\
OCPO & Organic carbon (hydrophobic) & $1.53+0.01 i$ & 0.117 & 0.25
\end{tabular}

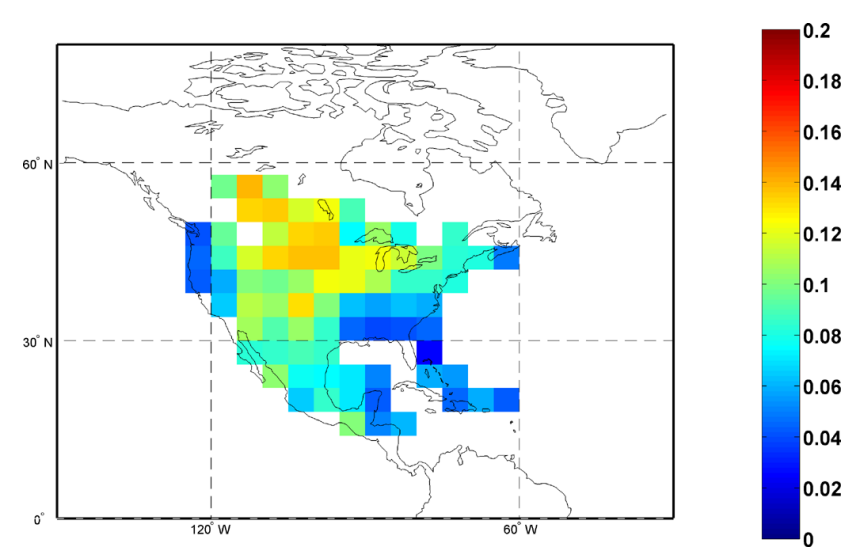

Fig. 2. Surface reflectivities over N. America for $646 \mathrm{~nm}$ incident radiation. Reflectivities have been averaged over the two week period of the model run.

the right hand sides of Eqs. (1) and (2) is discussed in the Appendix.

The GEOS-Chem adjoint model (Henze et al., 2007) is used to relate the sensitivities from Eq. (1) back to sensitivities with respect to emissions. In general, an adjoint model is used to calculate the dependence of metrics based on model output values (i.e., averaged polarized or radiant reflectances) to a set of input parameters (in this case, emissions). A full discussion of adjoint modeling can be found in works such as Giering and Kaminski (1998) or Sandu et al. (2005); here we present a brief summary. The goal of an adjoint model is to find the sensitivity of a scalar cost function, $J$, to a set of model parameters. Following the work of Henze et al. (2007, 2009), let $\boldsymbol{c}_{n}$ be a state vector of the aerosol concentrations at a certain model time step, $n$. The forward GEOS-Chem model, $F$, advances the state vector by one time step.

$c_{n+1}=F\left(c_{n}\right)$

This process is repeated until the model reaches the final time step, $N$, and the output aerosol concentration, $\boldsymbol{c}_{N}$. The goal is to determine the gradient of the cost function, evaluated with respect to the state vector at all other time steps in the model:

$\nabla_{c_{n}} J=\left(\frac{\partial J}{\partial c_{n}}\right)^{T}=\sum_{n^{\prime}=n}^{N}\left(\frac{\partial J^{n^{\prime}}}{\partial c_{n}}\right)^{T} \equiv \lambda_{c}^{n}$,

where $\lambda_{c}^{n}$ is the adjoint state variable. Using the chain rule, Eq. (4) can be expanded to show the dependence of the cost function to concentrations at all earlier time steps,

$$
\begin{aligned}
\lambda_{c}^{n} & =\left[\frac{\partial \boldsymbol{c}_{n+1}}{\partial \boldsymbol{c}_{n}}\right]^{T} \lambda_{c}^{n+1}+\left(\frac{\partial \boldsymbol{J}^{n}}{\partial \boldsymbol{c}_{n}}\right)^{T} \\
& =\left[\frac{\partial \boldsymbol{c}_{n+1}}{\partial \boldsymbol{c}_{n}}\right]^{T} \lambda_{c}^{n+1}+g^{n} .
\end{aligned}
$$

The dependence of the cost function to the concentrations at the current time step is described by the adjoint forcing, $g^{n}$. The approach to calculating the dependence of the cost function on the model inputs, such as initial concentrations or emissions, is to initialize the adjoint variable at the final time step (the adjoint forcing, $\lambda_{c}^{N}$ ), and then apply Eq. (5) iteratively for $n=N, N-1, \ldots 1$.

For this work, the cost function is defined as the spatiotemporal average of all model predictions for the TOA radiant reflectance or polarized reflectance calculated in the radiative transfer model as discussed in Sect. 2.2.

$J=\frac{1}{N_{\mathrm{RT}}} \sum_{n} R_{I, n} \quad$ or $\quad J=\frac{1}{N_{\mathrm{RT}}} \sum_{n} R_{P, n}$

The corresponding adjoint forcing terms are the derivatives of the cost function with respect to aerosol concentrations,

$g^{n}=\frac{1}{N_{\mathrm{RT}}}\left(\frac{\partial R_{I}^{n}}{\partial \boldsymbol{c}_{n}}\right)^{T} \quad$ or $\quad g^{n}=\frac{1}{N_{\mathrm{RT}}}\left(\frac{\partial R_{P}^{n}}{\partial \boldsymbol{c}_{n}}\right)^{T}$,

where $N_{\mathrm{RT}}$ is the number of radiative calculations of the polarization or intensity used in the adjoint calculations and the summation $n$ is over the temporal and spatial extent of the radiative transfer calculations, i.e., over each simulated observation throughout the two week time period of the simulation. As can be seen in Eq. (7), it is first necessary to calculate the sensitivities with respect to the aerosol concentrations (Eq. 1) in order to determine the adjoint forcing terms. 


\section{Model configurations}

Here we describe model settings, input parameters, and simulated observations that were used in the model runs. All simulations spanned a two week period running from 1 April 2008 to 15 April 2008. Aerosol concentrations for seven aerosol species are calculated by GEOS-Chem on a $4^{\circ} \times 5^{\circ}$ resolution global grid. The reflectances at TOA along with the relevant Jacobian matrices are calculated over the two week time frame. Data is constrained to regions over N. America. Surface reflectivities are derived using a 40 day rolling average of the reflectivities from the MODIS level 4 data product. This is done on a pixel-by-pixel basis for the MODIS input data, using two evenly-spaced simulated satellite observation grids discussed below.

Two different simulated observation grids are used in the radiative transfer calculations (see Fig. 3) in order to model typical instrumental specifications from satellites able to make intensity-based (MODIS, MISR) or polarimetric observations (POLDER, APS). The first is an evenly spaced grid where pixels are sampled from every 20th column and 20th row of the MODIS native grid. This grid will be referred to as the wide-swath grid. A second grid is generated to be similar to that of the failed Glory satellite, which was to have a much narrower ground track, only $\sim 5.6 \mathrm{~km}$ wide (Mishchenko et al., 2004, 2007). An alternative approach would have been to approximate the much wider observational swath of the POLDER instrument, $\sim 1600 \mathrm{~km}$ (Fougnie et al., 2007; Tanré et al., 2011). We chose to model the APS instrument for this work as it can be seen as a more extreme example of a possible limitation in polarimetric as opposed to intensity based measurements. To simulate the Glory observational track in our model, the MODIS native grid is only sampled along the row directly below the satellite (row 68) and at every 20th column. This grid will be referred to as the narrow-swath grid. Two separate sets of reflectances are then calculated, one for each grid. In each case, each pixel in each of the simulated observation grids is forced to pass quality assurance tests (no null data, reasonable signal levels, etc.) and must meet clear sky criteria (cloud free) prior to being used in the calculations. Failure to pass these tests resulted in the removal of that pixel from the grid.

For calculations of the sensitivities of the reflectance to aerosol and aerosol precursor emissions, discussed in Sect. 2.3, the adjoint model is run twice, once for each simulated satellite observation grid. The cost function, $J$, is defined based on the type of grid used in the radiative transfer calculations; see Eqs. (6) and (7). For the wide-swath grid, the cost function is set equal to the average radiant reflectance over the North American region (i.e., the region for which the radiative transfer calculations are performed). A total of $N_{\mathrm{RT}}=729$ pixels from the wide-swath grid passed the pixel quality checks for the radiative transfer calculations. For the narrow-swath grid, the polarized reflectance, rather than the radiant reflectance, is used for the cost function.

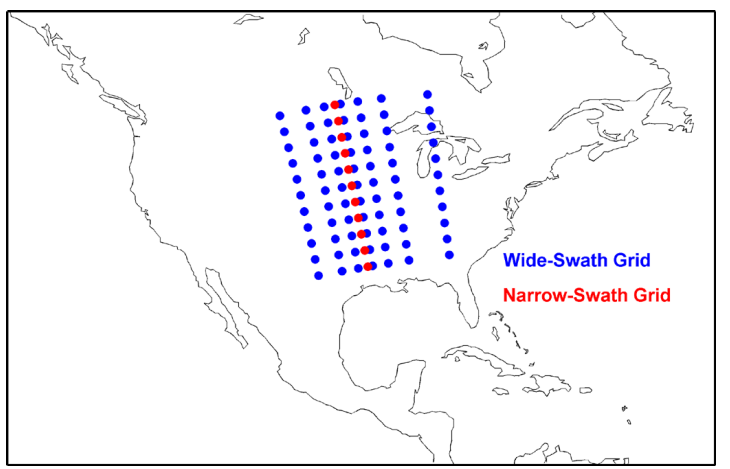

Fig. 3. Simulated satellite grids used in the radiative transfer calculations. The wide-swath grid (blue) is based on the MODIS instrument specifications and was used for the intensity based calculations. The narrow-swath grid (red) is based on the APS instrument aboard the failed Glory satellite and is used for polarimetric based calculations.

Since this grid is narrower, fewer pixels were available for use in the radiative transfer calculations, $N_{\mathrm{RT}}=91$.

\section{Results}

\subsection{Sensitivity validation}

The radiative transfer model has been verified by comparing the analytic derivation of the reflectance sensitivities with respect to the aerosol concentrations, microphysical properties, and emissions (Eqs. 1,2) to those generated using a second order finite difference (FD) test, as shown in Eq. (8) for concentrations,

$\frac{\mathrm{d} R}{\mathrm{~d} C} \approx \frac{R(C+\delta C)-R(C-\delta C)}{2 \delta C}$.

For the validations of the reflectance sensitivities to aerosol concentrations, the initial concentration of one aerosol species was perturbed in one atmospheric layer and the TOA reflectance was calculated. This was repeated for each atmospheric layer and for a number of aerosol species. For these tests, the perturbations to the concentrations were of the order $\delta=0.005$ to 0.2 depending on the aerosol species. The magnitude of the perturbation tended to be higher for species with lower concentrations (black carbon) and those where a large fraction of the aerosol concentrations were located near the surface. These aerosols tended to contribute fractionally less to the TOA reflectance and larger perturbations were therefore necessary to cause numerically significant changes in the reflectance.

Validation tests were also performed for the sensitivities to microphysical properties. For these tests, a single microphysical property $\left(n, k, r_{\text {eff }}\right.$, or $\left.v_{\text {eff }}\right)$ input to the Mie code was perturbed for one aerosol species. The magnitude of these perturbations ranged from $\delta=0.05-0.2$ depending on the aerosol species and the microphysical property being 
perturbed. The new perturbed Mie output was then used in the radiative transfer algorithm to generate a new set of TOA reflectances. This process was repeated multiple times for different microphysical properties and aerosol species.

For the tests of the reflectance sensitivity to emissions, perturbations were performed by applying scaling factors, $\delta=0.05$ and -0.05 , to one set of emissions for one aerosol species in separate runs of the forward GEOS-Chem model. Horizontal transport was disabled in order to evaluate FD sensitivities in multiple columns simultaneously. The aerosol concentrations generated by the perturbed forward model were then used as inputs to the radiative transfer code. This allowed for a second order approximation of the sensitivities in the finite difference tests using Eq. (8).

The validation results for selected aerosol species are shown in Fig. 4. In all plots, the sensitivities have been normalized by the magnitude of the reflectance and by the aerosol concentrations or emissions where applicable. For these plots, the model sensitivities are plotted along the $x$ axis while the results of the finite difference calculations are plotted along the $y$ axis. Perfect agreement between the two calculations would therefore appear as a straight line with a slope of one (black dashed line). A linear fit to the validation points, red dashed line, along with corresponding slopes and coefficients of determination, $R^{2}$, are included for each plot. The first row shows the agreement between the model results ( $x$ axis) and the finite difference tests ( $y$ axis) for the normalized sensitivities of the TOA polarized reflectance to aerosol concentrations, $\frac{C}{R_{\mathrm{p}}} \frac{\mathrm{d} R_{\mathrm{P}}}{\mathrm{d} C}$, for hydrophilic black carbon and sulfate. Results from the perturbations of the aerosol microphysical properties, $\frac{x}{R_{\mathrm{p}}} \frac{\mathrm{d} R_{\mathrm{P}}}{\mathrm{d} x}$, are shown in the second row. Sensitivities of the polarized reflectance to the effective variance of the size distribution of ammonium are shown on the left and the sensitivities to the effective radius of the size distribution for organic carbon on the right. The bottom row contains the validations of the sensitivities to emissions, $\frac{E}{R_{\mathrm{p}}} \frac{\mathrm{d} R_{P}}{\mathrm{~d} E}$, of black carbon (left) and ammonia (right). As can be seen, the analytic results derived from the model and those generated using finite difference analysis are in very good agreement for all reflectance sensitivities with the exception of a few outliers that can be expected from finite difference approximations of systems containing non-linearities and discontinuities.

We have chosen to report all sensitivities of the TOA reflectances in this work in terms of normalized sensitivities, $\frac{x}{R} \frac{\mathrm{d} R}{\mathrm{~d} x}$. This has been done to facilitate easier comparison of the sensitivities between different aerosol species and between different aerosol properties. The magnitudes of the independent variables for which we are calculating the sensitivities with respect to, i.e., the aerosol concentrations or microphysical properties, can differ by orders of magnitude. By normalizing the sensitivities, we are able to instead present the percent change in the reflectance for some percent change in the aerosol properties.
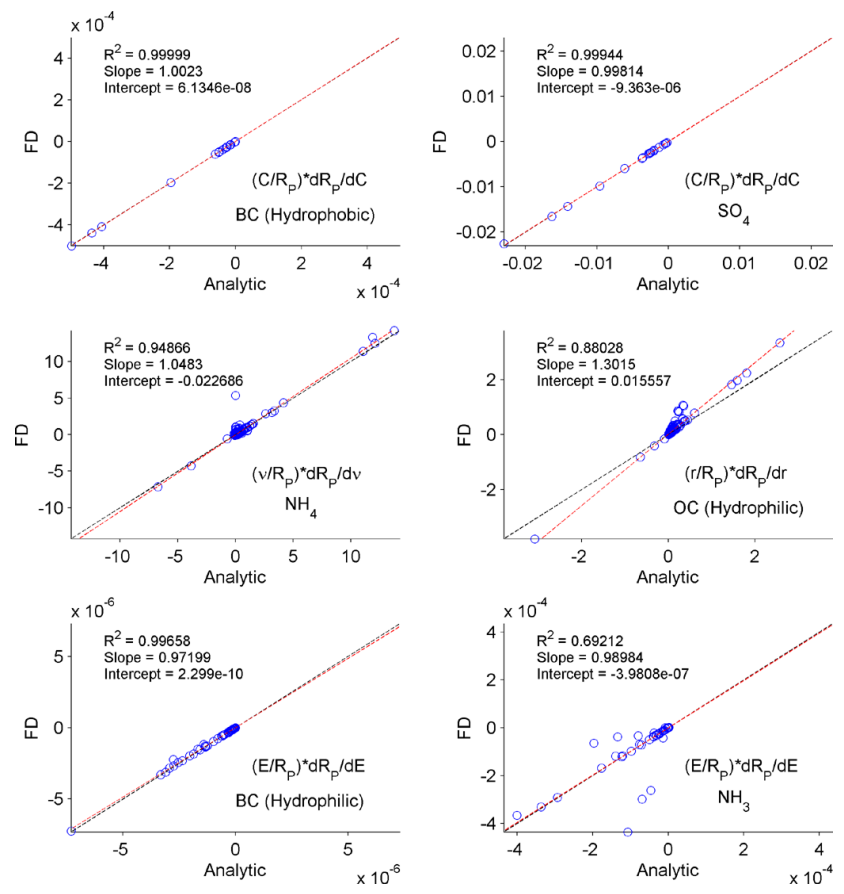

Fig. 4. Model validation comparing analytic model results ( $x$ axis) to finite difference calculations ( $y$ axis). Validation for the normalized sensitivity of the polarized reflectance to aerosol concentration is shown (top row) for hydrophobic black carbon (left) and sulfate aerosol (right). Results for validation of the sensitivity of TOA polarized reflectance to aerosol microphysical parameters is given (middle row) for sensitivity to the variance of the size distribution of ammonium (left) and the effective radius of hydrophobic organic carbon (right). The bottom row shows validations of the normalized sensitivity of the polarized reflectance to hydrophilic black carbon emissions (left) and to ammonia emissions (right).

\subsection{Sensitivities to aerosol concentrations}

The column integrated aerosol concentrations, as calculated by the GEOS-Chem model, are shown in Fig. 5. The values shown are the average concentrations over the entire two week time period of the model run. The normalized sensitivities of the polarized reflectance to the aerosol concentration, $\frac{C_{i}}{R_{\mathrm{P}}} \frac{\mathrm{d} R_{\mathrm{P}}}{\mathrm{d} C_{i}}$, of four aerosol species are shown in Fig. 6. The results include all pixels used in the calculations over a two week period (i.e., multiple satellite overpasses and multiple viewing geometries). Aerosol species used in this test include sulfate, ammonium, nitrate, and hydrophilic organic and black carbon. As was discussed in Sect. 2.2, the sensitivities of the reflectances to aerosol concentration and microphysical properties were calculated at 20 atmospheric layers. For ease of presentation, the sensitivities shown in Fig. 6 have been integrated over all of the atmospheric layers for which they were calculated, i.e., over the entire atmospheric column (Eq. 9). 


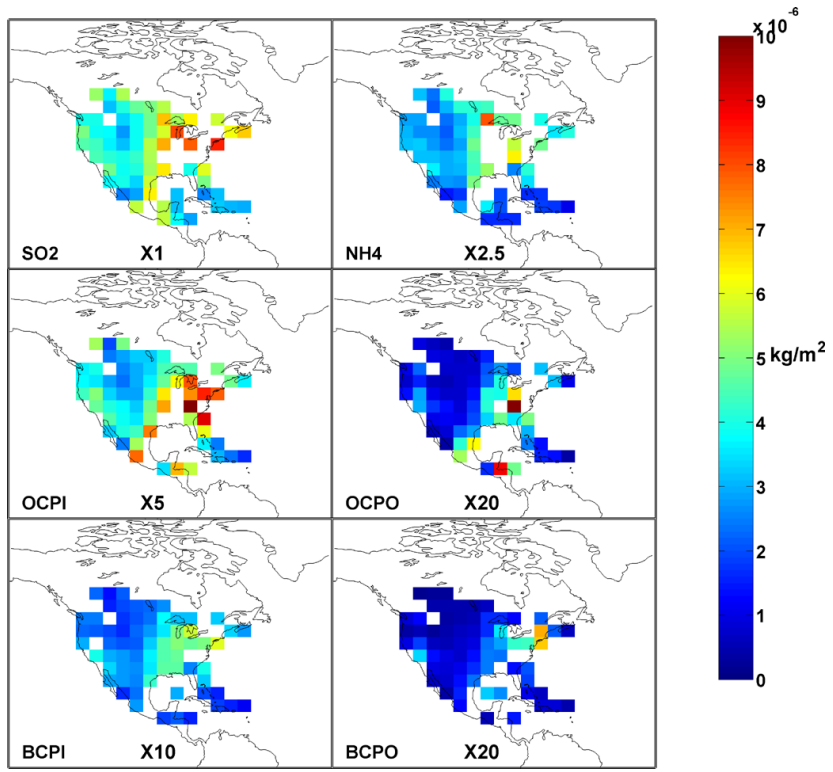

Fig. 5. Aerosol concentrations $\left(\mathrm{kg} \mathrm{m}^{-2}\right)$ for sulfate and ammonium (top row), hydrophilic and hydrophobic organic carbon (middle row), and hydrophilic and hydrophobic black carbon (bottom row). For cases where multiplicative value is present on an axis, the concentrations have been scaled by this value to make comparison between aerosol species easier.

$\frac{C_{i}}{R} \frac{\mathrm{d} R}{\mathrm{~d} C_{i}}=\frac{1}{R} \sum_{L=1}^{20} C_{i}(L) \frac{\mathrm{d} R}{\mathrm{~d} C_{i}(L)}$

Above, $L$ denotes the atmospheric layers and $C_{i}(L)$ is the concentration at layer $L$. Equivalent normalized summations have been used in reporting the sensitivities to the aerosol microphysical properties. The sensitivities to aerosol concentrations, averaged over N. America for the entire 2 week time period for each of the grids, are given in Table 2. All sensitivities given have been scaled by a factor of 100 for clarity.

The sensitivities calculated on the wide-swath grid are shown in Fig. 6a. As is stated earlier, the wide-swath grid is primarily used for calculations of the sensitivity of the TOA radiant, not the polarized, reflectance. It was, however, used in calculations of the polarized reflectance here for comparative purposes. In each case, the polarized reflectance sensitivity to aerosol concentrations tends to be negative, i.e., increasing aerosol concentrations in the atmosphere are expected to decrease the degree of polarization of TOA reflected light. There does appear to be some degree of spatial variability in these sensitivities, with slightly higher magnitude sensitivities for observations in the eastern United States. It must be reiterated that the sensitivities shown here are for viewing geometries determined by the Aqua satellite. The TOA Stokes parameters, from which the reflectances are derived, are dependent on the viewing geometry, specifically the azimuthal viewing angle since the zenith viewing angles

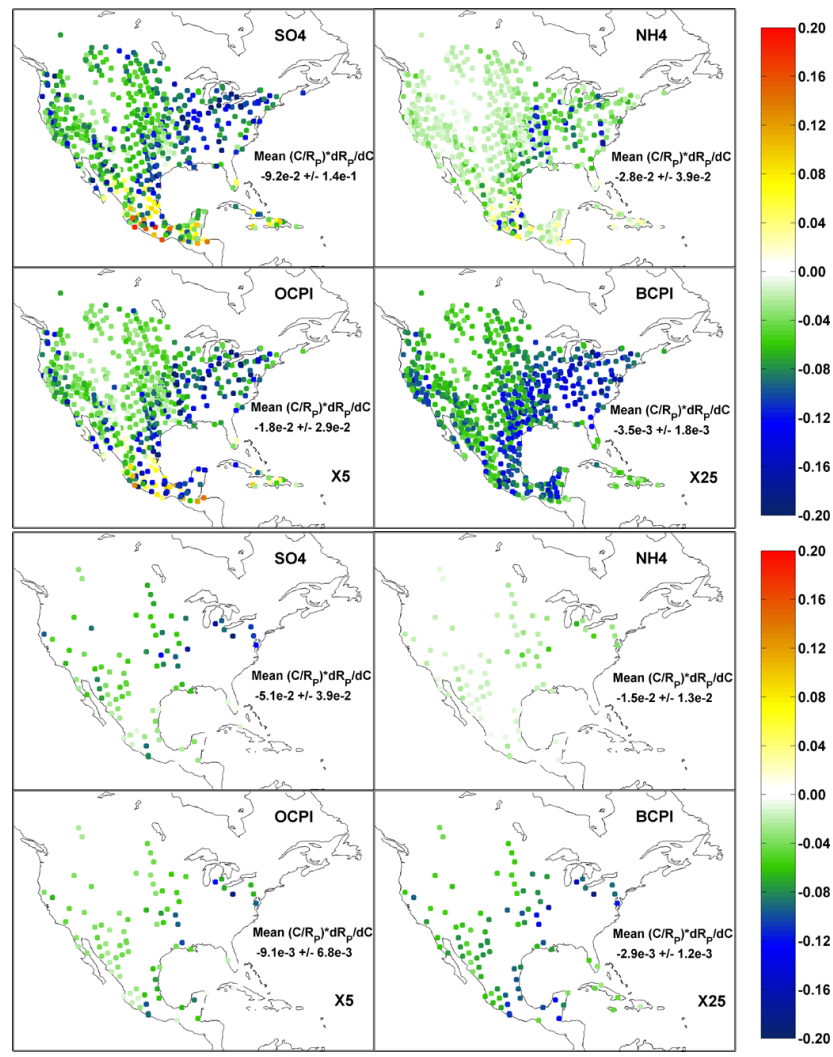

Fig. 6. Column integrated normalized sensitivities (Eq. 9) of the TOA polarized reflectance to aerosol concentrations of sulfate, ammonium, and hydrophilic organic and black carbon. For cases where multiplicative value is present on an axis, the sensitivities have been scaled by this value to make comparison between aerosol species easier. Results are given for radiative transfer calculations based on both the wide-swath grid (a) and the narrow-swath grid (b).

are constrained to nadir views only. Though some of the variability seen in the sensitivities in Fig. 6a is due to spatial variations in surface reflectivities, it is also due to the dependence of the Stokes parameters on viewing geometry, with some viewing angles producing higher sensitivities to the aerosol concentrations. It was seen in calculations of single wideswath grids (i.e one observation time) that large azimuthal angles (measured from the satellite flight path) tend to produce sensitivities that are of a larger magnitude compared to those that are observed directly along the satellite flight path. This can be seen most clearly by comparing the results for the wide-swath grid with those that were calculated using the narrow-swath satellite grid, Fig. 6b. In this case only pixels directly below the satellite were used in the calculations; the viewing azimuthal angle was constrained to $0^{\circ}$. Not only is the mean sensitivity of the polarized reflectance to aerosol concentration smaller, but the relative variations in the sensitivities are much smaller for all aerosol species. We suspect this dependence of the viewing geometry on azimuthal angle is due to two factors, the angular dependence of the single 


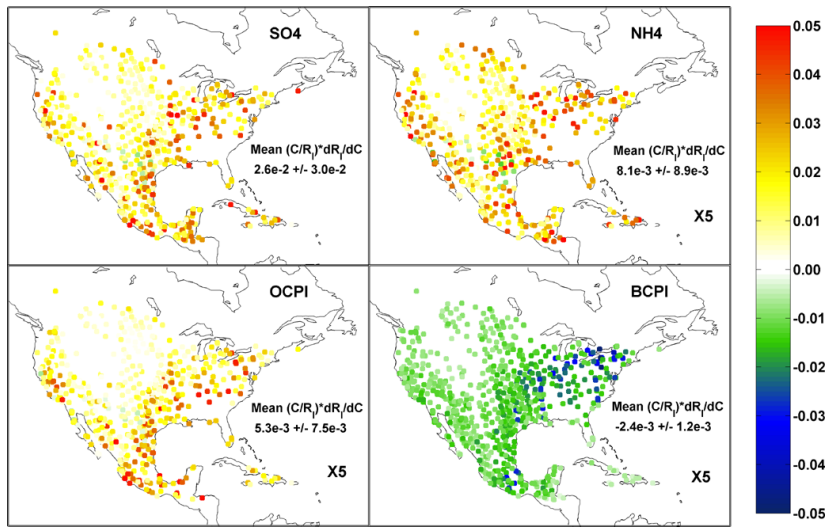

Fig. 7. Normalized TOA radiant reflectance sensitivities (Eq. 9) to aerosol concentrations for sulfate, ammonium, and hydrophilic organic and black carbon. For cases where multiplicative value is present on an axis, the sensitivities have been scaled by this value to make comparison between aerosol species easier. Results are given for radiative transfer calculations based on the wide-swath grid.

aerosol light scattering properties (phase function and polarization profile) and the increase in path length for the more extreme azimuthal angles. As the path length increases, the interaction between incident solar radiation and the aerosols within that path will increase resulting in a higher sensitivity to the aerosol properties.

It is also possible that the larger sensitivities seen in the eastern US may be due to coupling of the sensitivities to the concentrations of other aerosol species. Since the sensitivities to aerosol concentrations of a given species presented in Fig. 6 are normalized by the concentration of that species, we do not expect the sensitivities to show a spatial dependence that correlates with the concentrations of that species. However, it may be that larger relative changes in the concentrations of the other aerosol species may affect these sensitivities. For example, it can be seen in Fig. 5 that there is a larger relative difference in the concentrations of BCPI and OCPI on the eastern US than is seen in the western US. It is possible that these relatively higher concentrations of OCPI could contribute to a spatial dependence in the BCPI sensitivities. These cross correlated effects have not been explored thoroughly in this work however.

Similar calculations were made for the sensitivities of the radiant reflectance to the aerosol properties. These results are shown in Fig. 7 for the wide-swath grid. It was found that the radiant reflectances tend to be less sensitive to aerosol concentrations for most species. The exception are aerosols that have large optical absorptance, i.e., large imaginary refractive index, such as black carbon. In most cases, $\frac{\mathrm{d} R_{I}}{\mathrm{~d} C}$ is positive - opposite in sign to what is calculated for $\frac{\mathrm{d} R_{P}}{\mathrm{~d} C}$. Increasing the aerosol concentrations leads to a higher amount of TOA scattering. Again this is not the case for absorbing aerosols, where $\frac{\mathrm{d} R_{I}}{\mathrm{~d} C}$ is negative, and increasing the concentration leads to an attenuation of TOA reflected light intensity.

Given that remote retrievals of aerosol concentrations are dependent upon assumptions of aerosol microphysical properties, calculations of the sensitivities of the radiant and polarized reflectances to aerosol size and optical properties are performed using both the narrow and wide swath grids respectively. The sensitivities to aerosol microphysics are not reported, but are used later in determining estimates of the allowable uncertainties in the aerosol microphysical properties that would be required for constraining aerosol emissions using the adjoint calculations (see Sect. 4.4).

\subsection{Sensitivities to aerosol emissions}

Figure 8 shows the results of the adjoint calculations of the sensitivity of the average TOA radiant reflectance over $\mathrm{N}$. America to global aerosol emissions, $\frac{E_{i}}{R_{I}} \mathrm{~d} R_{I}$, for the wideswath grid. It should be reiterated that these normalized sensitivities are calculated for aerosol emissions at all grid cells, using $4^{\circ} \times 5^{\circ}$ resolution, on a global grid. Since the values presented in Fig. 8 are normalized, the sensitivities of the reflectance to regions with very low emissions will be close to zero. Sensitivities are shown with respect to $\mathrm{SO}_{2}, \mathrm{NH}_{3}$, organic carbon and black carbon (hydrophilic and hydrophobic) emissions. Here $\mathrm{SO}_{2}$ is linked to the formation of sulfate aerosol through the oxidation of $\mathrm{SO}_{2}$ to sulfuric acid, then partitioning to the aerosol phase. Similarly, ammonium aerosol is linked to ammonia emissions through formation of ammonium nitrate and ammonium sulfate (Binkowski and Roselle, 2003).

The magnitudes of the sensitivities to emissions tend to be larger over the northeastern United States and over southern Mexico. These regions tend to have higher emissions and therefore higher aerosol concentrations, see Fig. 5. The normalized sensitivities reflect the impact of percent changes to existing emissions used in the GEOS-Chem model. Therefore some aspects of the different spatial patterns reflect differences in the spatial patterns of the emissions. The calculated radiant reflectances also show some dependence on emissions from southeastern Asia, particularly for ammonia and sulfur dioxide and for hydrophobic organic carbon to a lesser extent. Sensitivity to these non-local emissions shows the effects of the long distance transport of aerosols within the GEOS-Chem model (Yu et al., 2012, 2013). There is also a region of high sensitivities to ammonia emissions located over eastern Africa. Here, emissions of ammonia were high while those of sulfur dioxide were negligible during the two week time period examined here. Ammonium nitrate would therefore be the only secondary aerosol formed in that region. The model is therefore particularly sensitive to these ammonia emissions.

The calculations of the average TOA polarized reflectance sensitivity to global emissions, $\frac{E_{i}}{R_{P}} \frac{\mathrm{d} R_{P}}{\mathrm{~d} E_{i}}$, are given in Fig. 9. For these calculations, the narrow-swath grid is used in the 
Table 2. Average normalized sensitivities along with the range of values within 1 standard deviation of the mean of the TOA polarized reflectance, $R_{P}$, or reflectance, $R_{I}$, with respect to the concentration of each aerosol species considered in this work. Values are given for calculations using both the wide-swath (WS) and narrow-swath (NS) grids discussed in Sect. 2.2. All values have been scaled by a factor of 100 for ease in comparing the results.

\begin{tabular}{lrrrr}
\hline Aerosol & $\frac{C}{R_{P}} \frac{\mathrm{d} R_{P}}{\mathrm{~d} C}(\mathrm{WS})$ & $\frac{C}{R_{I}} \frac{\mathrm{d} R_{I}}{\mathrm{~d} C}(\mathrm{WS})$ & $\frac{C}{R_{P}} \frac{\mathrm{d} R_{P}}{\mathrm{~d} C}(\mathrm{NS})$ & $\frac{C}{R_{I}} \frac{\mathrm{d} R_{I}}{\mathrm{~d} C}(\mathrm{NS})$ \\
\hline $\mathrm{SO}_{4}$ & $-9.0 \pm 1.4$ & $2.6 \pm 3.0$ & $-5.1 \pm 3.9$ & $1.0 \pm 1.2$ \\
$\mathrm{NH}_{4}$ & $-2.8 \pm 3.9$ & $0.8 \pm 0.9$ & $-1.5 \pm 1.3$ & $0.3 \pm 0.4$ \\
$\mathrm{NIT}$ & $-1.7 \pm 2.3$ & $0.4 \pm 0.6$ & $-1.1 \pm 1.1$ & $0.2 \pm 0.2$ \\
$\mathrm{BCPI}$ & $-0.4 \pm 0.2$ & $-0.2 \pm 0.1$ & $-0.3 \pm 0.1$ & $-0.2 \pm 0.1$ \\
$\mathrm{OCPI}$ & $-1.8 \pm 2.9$ & $0.5 \pm 0.8$ & $-0.9 \pm 0.7$ & $0.2 \pm 0.2$ \\
$\mathrm{BCPO}$ & $-0.07 \pm 0.06$ & $-0.06 \pm-0.06$ & $-0.06 \pm .06$ & $-0.06 \pm 0.05$ \\
OCPO & $-0.2 \pm 0.3$ & $0.04 \pm 0.08$ & $-0.1 \pm 0.2$ & $0.02 \pm 0.03$ \\
\hline
\end{tabular}

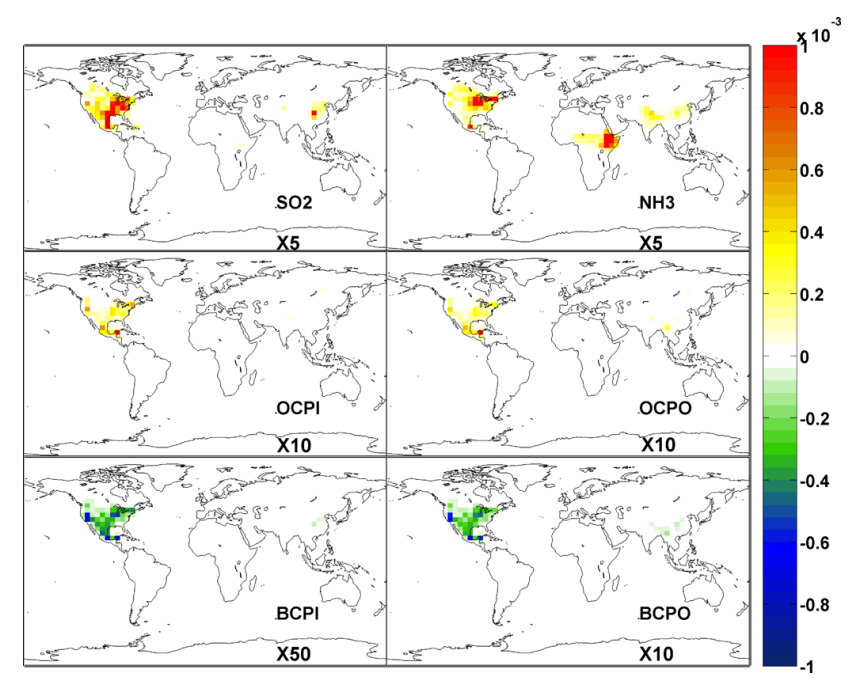

Fig. 8. Normalized sensitivity of TOA radiant reflectance to aerosol emissions, $\frac{E}{R_{I}} \frac{\mathrm{d} R_{I}}{\mathrm{~d} E}$, for sulfur dioxide and ammonia (top row), hydrophilic and hydrophobic organic carbon (middle row), and hydrophilic and hydrophobic black carbon (bottom row). For cases where a multiplicative value is present on an axis, the sensitivities have been scaled by this value to make comparison between aerosol species easier. Radiative transfer calculations were performed using the wide-swath grid.

radiative transfer equations. The spatial distribution of these sensitivities is similar to that seen in Fig. 8 with the highest sensitivities to emissions of sulfur dioxide and the carbonaceous aerosols from the eastern United States and Mexico City and to ammonia emissions from the midwestern United States. Similar to what was seen above for the radiant reflectances, the average polarized reflectance over N. America is dependent on emissions from eastern Asia. These sensitivities to intercontinental emissions are particularly strong for ammonia and hydrophobic black carbon emissions.

In order to perform a qualitative comparison between the sensitivities of the radiant reflectances calculated on the wide-swath to the polarized reflectances calculated on the

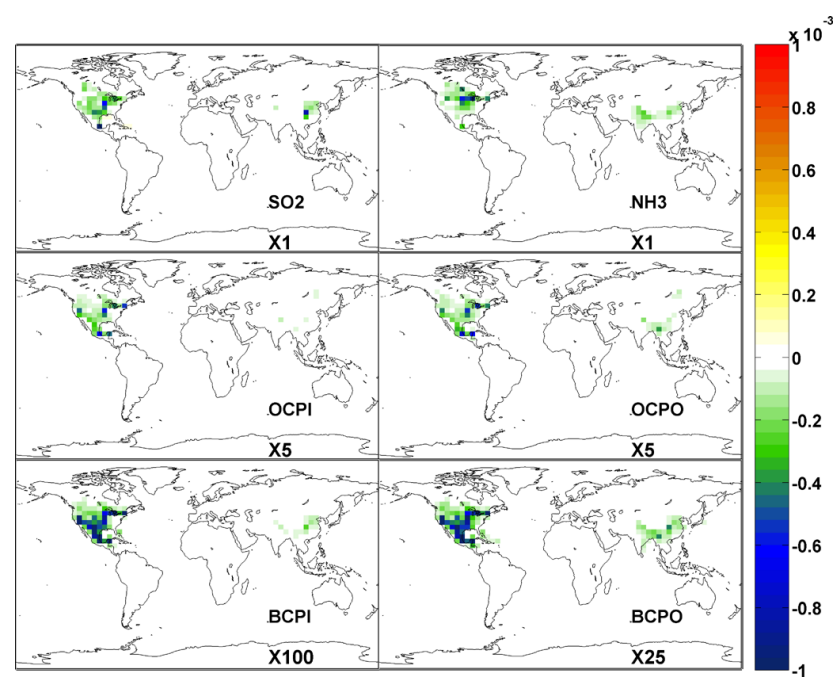

Fig. 9. Normalized sensitivity of TOA polarized reflectance to aerosol emissions, $\frac{E}{R_{P}} \frac{\mathrm{d} R_{P}}{\mathrm{~d} E}$, for sulfur dioxide and ammonia (top row), hydrophilic and hydrophobic organic carbon (middle row), and hydrophilic and hydrophobic black carbon (bottom row). For cases where a multiplicative value is present on an axis, the sensitivities have been scaled by this value to make comparison between aerosol species easier. Radiative transfer calculations were performed using the narrow-swath grid.

narrow-swath grid, the ratio of the magnitude of the normalized polarized reflectance sensitivity to the normalized radiant reflectance sensitivity is given in Fig. 10. In generating these ratios, small values $\left(\vartheta 10^{-6}\right)$ are excluded to avoid infinities that would obscure the regions of interest. For all of the aerosol species investigated in this work, the spatially averaged ratio is greater than 1 . The polarized reflectance tends to be more sensitive to aerosol emissions than the radiant reflectance by a factor $\sim 3$ for sulfur dioxide, ammonia, and organic carbon. In the case of these weakly absorbing aerosols, the ratio tends to be large for simulated measurements over the central United States. This corresponds to regions with lower aerosol concentrations as well as higher 


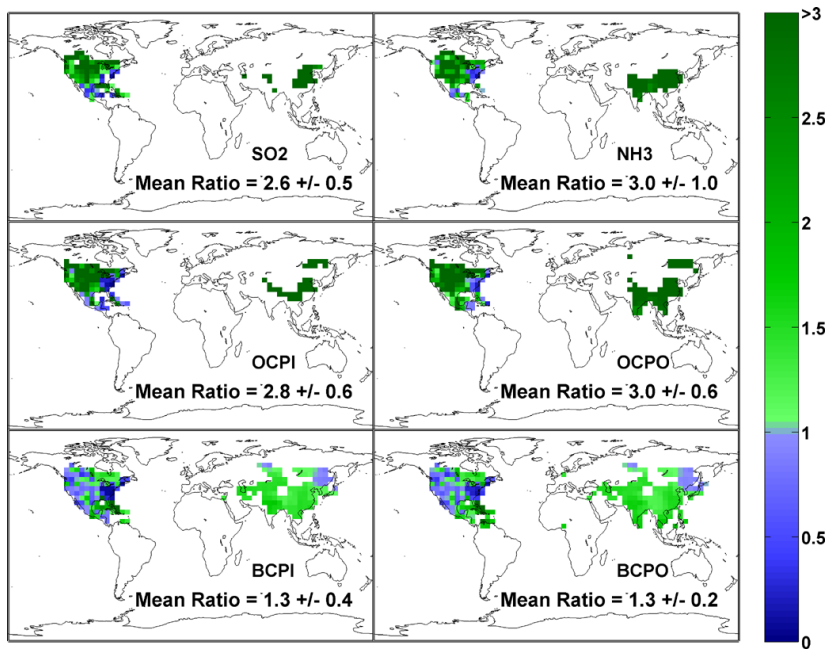

Fig. 10. Comparison of the magnitude of the sensitivities of the TOA polarized reflectance to emissions to the radiant reflectance sensitivities to emissions. Values shown are the absolute value of the ratios of the normalized sensitivity of the polarized reflectance to emissions, $\frac{E}{R_{P}} \frac{\mathrm{d} R_{P}}{\mathrm{~d} E}$, to the normalized sensitivity of the radiant reflectance to emissions, $\frac{E}{R_{I}} \frac{\mathrm{d} R_{I}}{\mathrm{~d} E}$. Results are shown for sulfur dioxide and ammonia (top row), hydrophilic and hydrophobic organic carbon (middle row), and hydrophilic and hydrophobic black carbon (bottom row).

surface reflectivities, see Figs. 5 and 2 respectively. However, lower values of the ratio are seen in the Caribbean and the eastern US coast. Here, the aerosol concentrations are again relatively low, but the surface reflectivities in this case are much lower. This suggests variations in this ratio are due to spatial variations in the surface albedo. These regions also exhibited higher relative humidities during the time period of these calculations, which will affect the aerosol optical properties and therefore the reflectance sensitivities. For the absorbing aerosols, a similar spatial distribution is seen in the ratio, though the magnitude of the ratio for black carbon is much lower, $\sim 1.3$. This is consistent with the results of Sect. 4.2 where it was shown that the percent change in the radiant reflectance for a given percent change in the aerosol concentrations was small for the highly scattering aerosols, but larger for absorbing aerosols when compared to the polarized reflectance sensitivities.

It should be reiterated that in remote measurements of the polarized reflectance, the radiant reflectance at the TOA is also acquired (Fougnie et al., 2007; Mishchenko et al., 2007). Even though the ratio of the sensitivities to black carbon emissions is closer to 1 , i.e., the polarimetric measurements are only slightly more sensitive to emissions, the intensity based information would be obtained along with the polarimetric measurements. If the sensitivities of the simulated polarimetric and intensity based measurements are combined, the differences in the measuring capabilities of the two simulated satellites would be enhanced. To explore this, we have

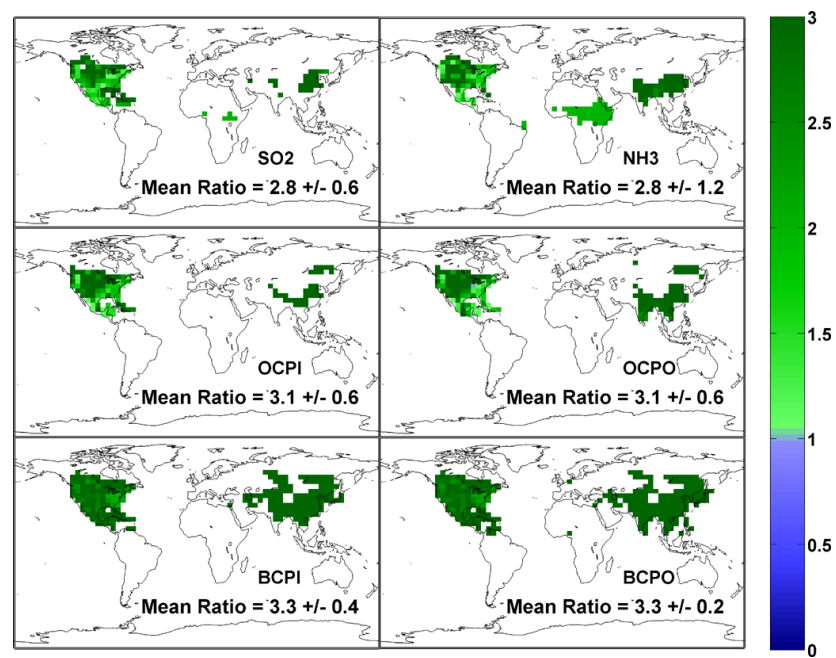

Fig. 11. Comparison of the sensitivities of the magnitude of the TOA total reflectance to the radiant reflectance sensitivities to emissions. Values shown are the absolute value of the ratios of the normalized sensitivity of the total reflectance to emissions, $\frac{E}{R_{T}} \frac{\mathrm{d} R_{T}}{\mathrm{~d} E}$, to the normalized sensitivity of the radiant reflectance to emissions, $\frac{E}{R_{I}} \frac{\mathrm{d} R_{I}}{\mathrm{~d} E}$. Results are shown for sulfur dioxide and ammonia (top row), hydrophilic and hydrophobic organic carbon (middle row), and hydrophilic and hydrophobic black carbon (bottom row).

also considered the case where the cost function is defined for the narrow swath grid using the total reflectance, $R_{T}$, defined as the sum of the averaged polarized and radiant reflectances,

$$
\begin{aligned}
& J=\frac{1}{N} \sum_{i}\left(R_{P, i}+R_{I, i}\right)=\frac{1}{N} \sum_{i} R_{T, i}, \\
& \frac{\partial J}{\partial C}=\frac{1}{N} \sum_{i}\left(\frac{\partial R_{P, i}}{\partial C_{i}}+\frac{\partial R_{I, i}}{\partial C_{i}}\right)=\frac{1}{N} \sum_{i} \frac{\partial R_{T, i}}{\partial C_{i}} .
\end{aligned}
$$

Comparisons of the sensitivities using this new cost function for the narrow swath grid to the radiant reflectance sensitivities to emissions calculated on the wide swath grid are shown in Fig. 11. In this formulation, it can be seen that the sensitivities of the total reflectance are of the same or greater magnitude than those obtained from intensity-only based measurements for all aerosol species investigated rather than just for the scattering aerosols. It can be seen that the largest increases in the sensitivities to emissions due to the implementation of the total reflectance are for black carbon. This is expected as the radiant reflectance sensitivities for this aerosol were of similar magnitude as those of the polarimetric reflectances seen in Fig. 10.

\subsection{Maximum allowable uncertainties in aerosol properties}

Though the primary focus of this work is examining the dependence of the radiant and polarized reflectances on aerosol 
emissions, both of these quantities are also functions of aerosol microphysical properties, wavelength, and viewing geometry (see Sect. 2.2). In order to gauge the accuracy with which we can determine the sensitivity of the reflectance to emissions, it is useful to determine how dependent the remote sensing constraints on emissions are to the aerosol microphysical parameters (aerosol size and optical properties) assumed in our model. We quantify this by determining the maximum uncertainties allowable in the input parameters that would still enable us to detect some predetermined change in the aerosol emissions, e.g., the maximum uncertainty in the input radius for sulfate aerosols that would result in smaller changes to the TOA reflectance than a $50 \%$ change in sulfate aerosol emissions. Though the retrieval of aerosol emissions is also sensitive to uncertainties in the surface reflectance and to the wavelength of the observations, these quantities were not varied in the radiative transfer calculations presented in this work and calculations have not been made for the effect of varying these quantities on retrieval of aerosol emissions.

Let $\Delta x$ be the uncertainty in one of the aerosol input parameters, $x$. The uncertainty in the calculated reflectance due to uncertainties in $x$ is then

$\Delta R_{x}=\Delta x \frac{\mathrm{d} R}{\mathrm{~d} x}$.

The goal is to find $\Delta R_{x} \leq \Delta R_{E}$, where $\Delta R_{E}$ is the uncertainty in the reflectance due to some set change in the aerosol emissions. Let the percent change in the aerosol emissions we would like to detect be given by $\varepsilon_{E}$, where $\Delta E= \pm \varepsilon_{E} E$. The percentage uncertainty in the aerosol parameter $x$ is then

$\varepsilon_{x}=\frac{\Delta x}{x} \leq \frac{\Delta E}{x}\left(\frac{\mathrm{d} R}{\mathrm{~d} E}\right)\left(\frac{\mathrm{d} R}{\mathrm{~d} x}\right)^{-1}$.

For these calculations, we have assumed a value of 0.5 for $\varepsilon_{E}$, i.e., a $50 \%$ change in the emissions. The uncertainties for each of the four aerosol input parameters $\left(n_{i} k_{i} r_{\mathrm{eff}, i} v_{\mathrm{eff}, i}\right)$ for each aerosol species were calculated for each pixel on the wide-swath grid, using $R_{I}$, and the narrow-swath grid, using $R_{P}$, in Eq. (13). The results are given in Table 3. Values of NA are given for percent uncertainties in cases where the aerosol input parameter is effectively zero (e.g., the imaginary refractive index, $k$, for non-absorbing aerosols).

For nearly all cases it is necessary to constrain the model input parameters to a higher degree of accuracy when performing the polarized reflectance calculations than is required for the radiant reflectance. This is expected as the polarized reflectance sensitivities tend to be higher than those of the radiant reflectance sensitivities as was seen in Sect. 4.3. Mishchenko et al. (2004) found that values of $\varepsilon_{r}=10 \%$, $\varepsilon_{v}=50 \%$, and $\varepsilon_{n}=1.5 \%$ are required for radiative forcing calculations that will be able to determine aerosol contributions to the Earth's total energy balance. The values predicted here for constraining aerosol emissions using polarimetric
Table 3. Maximum allowable relative uncertainties in the microphysical properties of each aerosol species required to constrain aerosol emissions within a factor of $50 \%$ for that species. Results are given assuming intensity based measurements, assuming a wide-swath grid, in (a) and polarimetric based measurements, assuming a narrow-swath grid, in (b). All values are given as a percentage uncertainty. Values reported as NA were not calculated as those values were effectively zero in the radiative transfer calculations.

\begin{tabular}{lrrrr}
\hline (a) Species & $\varepsilon\left(r_{\text {eff }}\right)$ & $\varepsilon\left(v_{\text {eff }}\right)$ & $\varepsilon(n)$ & $\varepsilon(k)$ \\
\hline BCPI & 0.8 & 0.05 & 2 & 1 \\
BCPO & 17 & 0.25 & 16 & 18 \\
OCPI & 9 & 0.8 & 0.3 & NA \\
OCPO & 52 & 2 & 0.8 & 45 \\
$\mathrm{NH}_{4}$ & 71 & 3 & 10 & NA \\
$\mathrm{SO}_{4}$ & 0.5 & 0.5 & 0.02 & $\mathrm{NA}$ \\
\hline (b) Species & $\varepsilon\left(r_{\text {eff }}\right)$ & $\varepsilon\left(v_{\text {eff }}\right)$ & $\varepsilon(n)$ & $\varepsilon(k)$ \\
\hline BCPI & 0.3 & 0.1 & 3 & 0.3 \\
$\mathrm{BCPO}$ & 9 & 2 & 20 & 7 \\
OCPI & 0.2 & 0.4 & 0.04 & $\mathrm{NA}$ \\
$\mathrm{OCPO}_{\mathrm{NH}}$ & 0.5 & 0.1 & 0.1 & 28 \\
$\mathrm{SO}_{4}$ & 6 & 2 & 3 & $\mathrm{NA}$ \\
\hline
\end{tabular}

measurements are within these constraints for the average uncertainty in the real refractive index $\left(\varepsilon_{n}=4 \%\right)$, but are much smaller for the average uncertainty in the effective radius $\left(\varepsilon_{r}=3 \%\right)$ and the average uncertainties allowed in the effective variance of the size distribution $\left(\varepsilon_{v}=1 \%\right)$. With the exception of the real refractive indices, these values are also smaller than the predicted uncertainties in the data products from the Glory satellite if its mission had been successful; which were estimated to be $\varepsilon_{r}=10 \%, \varepsilon_{v}=40 \%$, and $\varepsilon_{n}=1.5 \%$ (Mishchenko et al., 2007).

As was discussed in Sect. 4.3, the radiant reflectance information is often available along with the polarized reflectance in a typical remote sensing measurement. The radiant reflectance information could therefore be used in cases where it would be beneficial to do so over the polarimetric information. We ran another series of calculations where the radiant reflectance sensitivities were calculated using the narrow-swath grid and calculated the new maximum uncertainties using Eq. (13). It was found that the uncertainty limitations on the effective radius are met when using the radiant reflectance, $\varepsilon_{r}=25 \%$, though again not for the variance $\left(\varepsilon_{v}=1 \%\right)$. A combined set of polarimetric and radiant measurements of the reflectance would therefore only require better estimates of the effective variance of the size distribution of the aerosols in order to provide the $50 \%$ accuracies for constraining aerosol emissions for all of the species discussed here. This could possibly be achieved through improvements in the inversion algorithms used to derive those estimates for the variance or in the accuracy of the measurements themselves, 


\section{Discussion and conclusions}

A series of simulations were performed to assess the value of remote sensing measurements, such as those from the MODIS, APS, or POLDER instruments, to constrain aerosol emissions using the adjoint of the GEOS-Chem CTM. One set of simulated observations was restricted to measuring the radiant reflectance, proportional to the first element of the Stokes vector, while a second simulated measurement was capable of polarimetric measurements and could determine the polarized reflectance at the TOA. The ability to make polarimetric measurements comes at a cost; for example less spatial coverage per satellite pass (Glory) or a reduction in the number of wavelength bands that are able to be observed (POLDER) (Mishchenko et al., 2007; Fougnie et al., 2007). In this work, we sought to simulate the specifications of a typical polarimetric measurement platform by incorporating the use of a spatially limited observation grid for the polarimetric calculation to quantify the utility of using polarimetric measurements versus intensity based observations for constraining aerosol emissions.

It was found, for non-absorbing aerosols, that the sensitivity of TOA polarized reflectance is a factor of $\sim 3$ times more sensitive to aerosol emissions than that of TOA radiant reflectance even though the intensity calculations had a much larger spatial coverage. This is consistent with studies of single-particle light scattering calculations (Mishchenko and Travis, 1994), which find that particle size and shape play a larger role in determining the polarization state of the light than that of the imaginary component of the refractive index. For these cases, it should be noted that instrumentation that is capable of polarimetric measurements tend to be also capable of intensity measurements, e.g., Glory or PARASOL (Fougnie et al., 2007; Mishchenko et al., 2007), as the radiant reflectance is derived from the first element of the Stokes vector, which is often obtained along with the second and third elements required for the polarized reflectance calculations. It would be conceivable to adjust any calculations for strongly absorbing aerosols, such as black carbon, to combine radiant and polarized reflectance measurements in order to enhance sensitivities to aerosol properties.

All of the calculations of the polarimetric and intensity based sensitivities discussed in this work were calculated at only one viewing angle for our two simulated sets of measurements. It should be noted that including multiple viewing angles significantly increases the amount of information content in remote sensing measurements and allows for better retrieval of aerosol properties over an otherwise similar set of measurements with only one viewing angle (Kokhanovsky et al., 2010). A series of preliminary calculations of the polarimetric sensitivities to aerosol emissions have been performed using 12 viewing angles within the range of -60 to $50^{\circ}$. For these preliminary tests, it was assumed that the aerosol concentrations were constant for each viewing angle (i.e., no slant columns). It was found that by including these additional angles, the fractional change in the polarized reflectance for a given fractional change in the radiant reflectance increased by a factor of $\sim 1.5$ on average for different aerosol species. This suggests that the use of multiple viewing angles could significantly improve our ability to constrain aerosol emissions in future work.

It should also be noted that the results presented here were done assuming all simulated observations were performed at a wavelength of $650 \mathrm{~nm}$ using a predetermined sampling scheme (narrow and wide swath grids). It is assumed that results may differ for other wavelength bands or sampling schemes. Future work on this project will explore changes in the sensitivities for different wavelength bands. Work will also be done to incorporate satellite polarimetric measurements, such as those from the POLDER instrument (Tanré et al., 2011), into the adjoint model as a way of more accurately determining aerosol emissions.

\section{Appendix A}

Presented here is a brief derivation of the methods used to calculate the polarimetric sensitivities discussed in this work. Focus has been placed on the functional formulation of the reflectance and the calculation of its derivatives with respect to the aerosol optical and microphysical properties. A detailed discussion of radiative transfer theory and aerosol single scattering properties, which are necessary for the calculation of the Stokes vector, is beyond the scope of this article. An analysis of radiative transfer theory as well as approaches for determining both analytic and numeric solution strategies for the radiative transfer equation are presented in a wide body of literature (Chandrasekhar, 1960; Zaneveld et al., 2005; Mishchenko, 2002, 2003; Mishchenko et al., 1999; Spurr, 2006, 2008). For detailed derivations of the equations governing single particle and particle ensemble interactions with light using Mie or T Matrix theories, see works by Bohren and Huffman (1983) or Mishchenko et al. $(2000,2002)$ respectively.

The complete polarization state of electromagnetic radiation is described by the four components of the Stokes vector, S:

$\mathbf{S}=\left(\begin{array}{c}I \\ Q \\ U \\ V\end{array}\right)$,

where $I$ describes the intensity, $Q$ and $U$ describe the degree of linear polarization (at $\pm 90^{\circ}$ and $\pm 45^{\circ}$ relative to a reference plane, respectively), and $V$ describes the degree of circular polarization. Here, we define the reflectance vector, $\boldsymbol{R}$, in terms of the Stokes vector as

$$
\boldsymbol{R}=\frac{\pi}{I_{0} \mu} \mathbf{S},
$$


where $I_{0}$ is the incident solar intensity to the Earth and $\mu$ is the cosine of the solar zenith angle. The reflectance, $R_{I}$, and the polarized reflectance, $R_{\mathrm{p}}$, are then defined as

$$
\begin{aligned}
& R_{I}=\boldsymbol{R}_{1}=\frac{\pi}{I_{0} \mu} I, \\
& R_{P}=\sqrt{\boldsymbol{R}_{2}^{2}+\boldsymbol{R}_{3}^{2}}=\frac{\pi}{I_{0} \mu} \sqrt{Q^{2}+U^{2}} .
\end{aligned}
$$

Above, contributions to the polarized reflectance from the circularly polarized light have been set to zero as this contribution tends to be negligible in atmospheric radiative transfer. In the following derivations, we will refer to both $R_{I}$ and $R_{\mathrm{p}}$ using a general reflectance value, $R$, for cases where equivalent equations exist for both quantities.

The polarization state of scattered light in the atmosphere depends on the optical properties of the atmosphere and therefore on the molecular and aerosol composition, Eq. (A5). Atmospheric optical properties are described in terms of the extinction optical depth, $\tau$, the single scattering albedo, $\omega$, and the scattering matrix, $\mathbf{F}$,

$$
\begin{aligned}
R & =R(I, Q, U, V)=R(\tau, \omega, \mathbf{F}), \\
\tau & =\sum_{i} \tau_{i}, \\
\omega & =\frac{\delta}{\tau}=\frac{\sum_{i} \omega_{i} \tau_{i}}{\sum_{i} \tau_{i}}, \\
\mathbf{F} & =\frac{\sum_{i} \tau_{i} \omega_{i} \mathbf{F}_{i}}{\sum_{i} \tau_{i} \omega_{i}} .
\end{aligned}
$$

The index $i$ is over the different aerosol species that are present in the atmospheric layer. As discussed in Tegen and Lacis (1996), the extinction optical depth for each aerosol species can be calculated from the real and imaginary components of the refractive indices, $n$ and $k$, the effective radius and variance of the aerosol size distribution, $r_{\mathrm{eff}}(\mathrm{m})$ and $\nu_{\mathrm{eff}}$, and the aerosol column mass concentration, $C\left(\mathrm{~kg} \mathrm{~m}^{-2}\right)$. The extinction efficiency is given by $Q_{\text {ext }}$ (unitless) and the particle density by $\rho\left(\mathrm{kg} \mathrm{m}^{-3}\right)$.

$$
\tau_{i}=\frac{3}{4} \frac{C_{i} Q_{\mathrm{ext}, i}(\mathrm{RH})}{\rho_{i} r_{\mathrm{eff}, i}(\mathrm{RH}=0 \%)}\left(\frac{r_{\mathrm{eff}, i}(\mathrm{RH})}{r_{\mathrm{eff}, i}(\mathrm{RH}=0 \%)}\right)^{2}
$$

The optical properties of the aerosols are dependent on both the physical (size, shape, orientation) and chemical (refractive indices) properties of the scattering particles in these interactions and hence

$$
R=R\left(n_{i} k_{i} r_{\mathrm{eff}, i} v_{\mathrm{eff}, i} C_{i}\right) .
$$

The sensitivity of the reflectance to the various aerosol properties can now be calculated using the chain rule as was given in Eqs. (1) and (2) and repeated below, Eqs. (A11) and (A15), for continuity. For the sensitivity of the reflectance to the aerosol concentration of the $i$ th aerosol species,

$$
\frac{\mathrm{d} R}{\mathrm{~d} C_{i}}=\frac{\partial R}{\partial \omega} \frac{\mathrm{d} \omega}{\mathrm{d} C_{i}}+\frac{\partial R}{\partial \tau} \frac{\mathrm{d} \tau}{\mathrm{d} C_{i}}+\frac{\partial R}{\partial \mathbf{F}} \frac{\mathrm{d} \mathbf{F}}{\mathrm{d} C_{i}} .
$$

The partial derivatives of the reflectance are calculated numerically in the model and are discussed in Sect. 2.2. The derivatives of the single scattering albedo, extinction optical depth, and scattering matrix with respect to the aerosol concentrations were determined from Eqs. (A6)-(A9).

$$
\begin{aligned}
\frac{\mathrm{d} \tau}{\mathrm{d} C_{i}} & =\frac{3}{4} \frac{Q_{\mathrm{ext}, i}(\mathrm{RH})}{\rho_{i} r_{\mathrm{eff}, i}(\mathrm{RH}=0 \%)}\left(\frac{r_{\mathrm{eff}, i}(\mathrm{RH})}{r_{\mathrm{eff}, i}(\mathrm{RH}=0 \%)}\right)^{2} \\
\frac{\mathrm{d} \omega}{\mathrm{d} C_{i}} & =\frac{\omega_{i}-\omega}{\tau} \frac{\mathrm{d} \tau}{\mathrm{d} C_{i}} \\
\frac{\mathrm{d} \mathbf{F}}{\mathrm{d} C_{i}} & =\frac{\omega_{i} \mathbf{F}_{i}-\omega_{i} \mathbf{F}}{\omega \tau} \frac{\mathrm{d} \tau}{\mathrm{d} C_{i}}
\end{aligned}
$$

In calculating the derivatives of the reflectance with respect to the aerosol physical and optical properties $\left(n, k, r_{\text {eff }}\right.$, and $v_{\text {eff }}$ ), the derivatives are again first expanded using the chain rule. In the following let $x_{i}$ represent any of $n_{i}, k_{i}, r_{\mathrm{eff}, i}$, and $v_{\text {eff }, i}$.

$$
\frac{\mathrm{d} R}{\mathrm{~d} x_{i}}=\frac{\partial R}{\partial \omega} \frac{\partial \omega}{\partial \omega_{i}} \frac{d \omega_{i}}{\mathrm{~d} x_{i}}+\frac{\partial R}{\partial \tau} \frac{\partial \tau}{\partial \tau_{i}} \frac{\mathrm{d} \tau_{i}}{\mathrm{~d} x_{i}}+\frac{\partial R}{\partial \mathbf{F}} \frac{\partial \mathbf{F}}{\partial \mathbf{F}_{i}} \frac{\mathrm{d} \mathbf{F}_{i}}{\mathrm{~d} x_{i}}
$$

The derivatives $\frac{\partial R}{\partial \omega} \frac{\partial R}{\partial \tau}$, and $\frac{\partial R}{\partial \mathbf{F}}$ are again calculated numerically in the VLIDORT model along with the derivatives $\frac{\mathrm{d} \omega_{i}}{\mathrm{~d} x_{i}}, \frac{\mathrm{d} \tau_{i}}{\mathrm{~d} x_{i}}$, and $\frac{\mathrm{d} \mathbf{F}_{i}}{\mathrm{~d} x_{i}}$. The derivatives of the total optical parameters with respect to the aerosol species specific parameters (i.e., $\frac{\partial \omega}{\partial \omega_{i}}, \frac{\partial \tau}{\partial \tau_{i}}$, and $\frac{\partial \mathbf{F}}{\partial \mathbf{F}_{i}}$ ) are determined analytically from Eqs. (A6)-(A8).

$$
\begin{aligned}
\frac{\partial \omega}{\partial \omega_{i}} & =\frac{\tau_{i}}{\tau} \\
\frac{\partial \tau}{\partial \tau_{i}} & =1 \\
\frac{\partial \mathbf{F}}{\partial \mathbf{F}_{i}} & =\frac{\tau_{i} \omega_{i}}{\tau \omega}
\end{aligned}
$$

Acknowledgements. The authors would like to thank Robert J. D. Spurr of RT Solutions for providing insight in regards to the modifications to the VLIDORT model. The authors would also like to thank Piet Stammes of the Royal Netherlands Meteorological Institute and the anonymous reviewers of this paper for their comments and suggestions. This work was funded under a grant from the NASA Glory science program (grant: NNX11AB91G).

Edited by: P. Stammes 


\section{References}

Alexander, B., Savarino, J. , Lee, C. C. W., Park, R. J., Jacob, D. J., Thiemens, M. H., Li, Q. B., and Yantosca, R. M.: Sulfate formation in sea-salt aerosols: Constraints from oxygen isotopes, $\mathrm{J}$. Geophys. Res., 110, D10307, doi:10.1029/2004JD005659, 2005.

Benedetti, A., Morcrette, J. J., Boucher, O., Dethof, A., Engelen, R. J., Fisher, M., Flentje, H., Huneeus, N., Jones, L., Kaiser, J. W., Kinne, S., Mangold, A., Razinger, M., Simmons, A. J., and Suttie, M.: Aerosol analysis and forecast in the European Centre for Medium-Range Weather Forecasts Integrated Forecast System: 2. Data assimilation, J. Geophys. Res.-Atmos., 114, D13205, doi:10.1029/2008JD011115, 2009.

Bey, I., Jacob, D. J., Yantosca, R. M., Logan, J. A., Field, B., Fiore, A. M., Li, Q., Liu, H., Mickley, L. J., and Schultz, M.: Global modeling of tropospheric chemistry with assimilated meteorology: Model description and evaluation, J. Geophys. Res., 106, 23073-23096, 2001.

Binkowski, F. S. and Roselle, S. J.: Models-3 Community Multiscale Air Quality (CMAQ) model aerosol component: 1. Model description, J. Geophys. Res., 108, 4183, doi:10.1029/2001JD001409, 2003.

Bodhaine, B. A., Wood, N. B., Dutton, E. G., and Slusser, J. R.: On Rayleigh Optical Depth Calculations, J. Atmos. Ocean. Tech., 16, 1854-1861, 1999.

Bohren, C. F. and Huffman, D. R.: Absorption and scattering of light by small particles, John Wiley, New York, 1983.

Bond, T. C., Bhardwaj, E., Dong, R., Jogani, R., Jung, S., Roden, C., Streets, D., and Trautman, N. M.: Historical emissions of black and organic carbon aerosol from energy-related combustion, 1850-2000, Global Biogeochem. Cy., 21, GB2018, doi:10.1029/2006GB002840, 2007.

Callies, J., Corpaccioli, E., Eisinger, M., Hahne, A., and Lefebvre, A.: GOME-2 - Metop's Second-Generation Sensor for Operational Ozone Monitoring, ESA Bulletin, 102, 2000.

Chandrasekhar, S.: Radiative Transfer, Dover Publications, 1960.

Chowdhary, J., Cairns, B., Mishchenko, M., and Travis, L.: Using multi-angle, multispectral photo-polarimetry of the NASA Glory mission to constrain optical properties of aerosols and clouds: Rresults from four field experiments, Proc. SPIE 5978, Sensors, Systems, and Next-Generation Satellites IX, 59780G, doi:10.1117/12.631201, 2005.

Deschamps, P.-Y., Breon, F.-M., Leroy, M., Podaire, A., Bricaud, A., Buriez, J.-C., and Seze, G.: The POLDER Mission: Instrument Charecteristics and Scientific Objectives, IEEE T. Geosci. Remote, 32, 598-615, 1994.

Deuze, J. L., Goloub, P., Herman, M., Marchand, A., Perry, G., Susana, S., and Tanre, D.: Estimate of the aerosol properties over the ocean with POLDER, J. Geophys. Res., 105, 15329-15346, doi:10.1029/2000JD900148, 2000.

Diner, D. J., Beckert, J. C., Reilly, T. H., Bruegge, C. J., Conel, J. E., Kahn, R. A., Martonchik, J. V., Ackerman, T. P., Davies, R., Gerstl, S. A. W., Gordon, H. R., Muller, J.-P., Myneni, R. B., Sellers, P. J., Pinty, B., and Verstraete, M. M.: Multi-angle Imaging SpectroRadiometer instrument description and experiment overview, IEEE T. Geosci. Remote, 36, 1072-1087, 1998.

Dubovik, O. and King, M. D.: A flexible inversion algorithm for retrieval of aerosol optical properties from Sun and sky radiance measurements, J. Geophys. Res, 105, 20673-20696, 2000.
Dubovik, O., Holben, B. N., Lapyonok, T., Sinyuk, A., Mishchenko, M. I., Yang, P., and Slutsker, I.: Non-spherical aerosol retrieval method employing light scattering by spheroids, J. Geophys. Res, 29, 1415, doi:10.1029/2001GL014506, 2002.

Dubovik, O., Lapyonok, T., Kaufman, Y. J., Chin, M., Ginoux, P., Kahn, R. A., and Sinyuk, A.: Retrieving global aerosol sources from satellites using inverse modeling, Atmos. Chem. Phys., 8, 209-250, doi:10.5194/acp-8-209-2008, 2008.

Dubovik, O., Herman, M., Holdak, A., Lapyonok, T., Tanré, D., Deuzé, J. L., Ducos, F., Sinyuk, A., and Lopatin, A.: Statistically optimized inversion algorithm for enhanced retrieval of aerosol properties from spectral multi-angle polarimetric satellite observations, Atmos. Meas. Tech., 4, 975-1018, doi:10.5194/amt-4975-2011, 2011

Fairlie, T. D., Jacob, D. J., and Park, R. J.: The impact of transpacific transport of mineral dust in the United States, Atmos. Environ., 41, 1251-1266, 2007.

Forster, P., Ramaswamy, V., Artaxo, P., Berntsen, T., Betts, R., Fahey, D. W., Haywood, J., Lean, J., Lowe, D. C., Myhre, G., Nganga, J., Prinn, R., Raga, G., Schulz, M., and Van Dorland, R.: Changes in Atmospheric Constituents and in Radiative Forcing, in: Climate Change 2007: The Physical Science Basis. Contribution of Working Group I to the Fourth Assessment Report of the Intergovernmental Panel on Climate Change, edited by: Solomon, S., Qin, D., Manning, M., Chen, Z., Marquis, M., Averyt, K. B., Tignor, M., and Miller, H. L., Cambridge University Press, Cambridge, United Kingdom and New York, NY, USA, 2007.

Fougnie, B., Bracco, G., Lafrance, B., Ruffel, C., Hagolle, O., and Tinel, C.: PARASOL in-flight calibration and performance, Appl. Optics, 46, 5435-5451, 2007.

Giering, R. and Kaminski, T.: Recipes for Adjoint Construction, ACM T. Math. Softw., 24, 437-474, 1998.

Guenther, A., Karl, T., Harley, P., Wiedinmyer, C., Palmer, P. I., and Geron, C.: Estimates of global terrestrial isoprene emissions using MEGAN (Model of Emissions of Gases and Aerosols from Nature), Atmos. Chem. Phys., 6, 3181-3210, doi:10.5194/acp-63181-2006, 2006.

Hansen, J., Sato, M., Lacis, A., and Ruedy, R.: The missing climate forcing, Phil. Trans. R. Soc. Lond. B, 352, 231-240, doi:10.1098/rstb.1997.0018, 1997.

Henze, D. K., Hakami, A., and Seinfeld, J. H.: Development of the adjoint of GEOS-Chem, Atmos. Chem. Phys., 7, 2413-2433, doi:10.5194/acp-7-2413-2007, 2007.

Henze, D. K., Seinfeld, J. H., and Shindell, D. T.: Inverse modeling and mapping US air quality influences of inorganic $\mathrm{PM}_{2.5}$ precursor emissions using the adjoint of GEOS-Chem, Atmos. Chem. Phys., 9, 5877-5903, doi:10.5194/acp-9-5877-2009, 2009.

Holben, B. N., Eck, T. F., Slutsker, I., Tanré, D., Buis, J. P., Setzer, A., Vermote, E., Reagan, J. A., Kaufman, Y., Nakajima, T., Lavenu, F., Jankowiak, I., and Smirnov, A.: AERONET - A federated instrument network and data archive for aerosol characterization, Remote Sens. Environ., 66, 1-16 1998.

King, M. D., Kaufman, Y. J., Tanre, D., and Nakajima, T.: Remote Sensing of Tropospheric Aerosols from Space: Past, Present, and Future, B. Am. Meteorol. Soc., 80, 2229-2259, 1999.

Kinne, S., Schulz, M., Textor, C., Guibert, S., Balkanski, Y., Bauer, S. E., Berntsen, T., Berglen, T. F., Boucher, O., Chin, M., Collins, 
W., Dentener, F., Diehl, T., Easter, R., Feichter, J., Fillmore, D., Ghan, S., Ginoux, P., Gong, S., Grini, A., Hendricks, J., Herzog, M., Horowitz, L., Isaksen, I., Iversen, T., Kirkevåg, A., Kloster, S., Koch, D., Kristjansson, J. E., Krol, M., Lauer, A., Lamarque, J. F., Lesins, G., Liu, X., Lohmann, U., Montanaro, V., Myhre, G., Penner, J., Pitari, G., Reddy, S., Seland, O., Stier, P., Takemura, T., and Tie, X.: An AeroCom initial assessment - optical properties in aerosol component modules of global models, Atmos. Chem. Phys., 6, 1815-1834, doi:10.5194/acp-6-1815-2006, 2006.

Knobelspiesse, K., Cairns, B., Mishchenko, M., Chowdhary, J., Tsigaridis, K., van Diedenhoven, B., Martin, W., Ottaviani, M., and Alexandrov, M.: Analysis of fine-mode aerosol retrieval capabilities by different passive remote sensing instrument designs, Opt. Express, 20, 21457-21484, doi:10.1364/OE.20.021457, 2012.

Koepke, P., Hess, M., Schult, I., and Shettle, E. P.: Global Aerosol Data Set, Rep. No. 243, Max-Planck-Institut fur Meteorol., Hamburg, Germany, 1997.

Kokhanovsky, A. A., Deuzé, J. L., Diner, D. J., Dubovik, O., Ducos, F., Emde, C., Garay, M. J., Grainger, R. G., Heckel, A., Herman, M., Katsev, I. L., Keller, J., Levy, R., North, P. R. J., Prikhach, A. S., Rozanov, V. V., Sayer, A. M., Ota, Y., Tanré, D., Thomas, G. E., and Zege, E. P.: The inter-comparison of major satellite aerosol retrieval algorithms using simulated intensity and polarization characteristics of reflected light, Atmos. Meas. Tech., 3, 909-932, doi:10.5194/amt-3-909-2010, 2010.

Liu, H., Jacob, D. J., Bey, I., and Yantosca, R. M.: Constraints from ${ }^{210} \mathrm{~Pb}$ and ${ }^{7} \mathrm{Be}$ on wet deposition and transporting a global threee-dimensional chemical tracer model driven by asimilated meteorological fields, J. Geophys. Res., 106, 12109-12128, 2001.

Mari, C., Jacob, D. J., and Bechtold, P.: Transport and scavenging of soluble gases in a deep convective cloud, J. Geophys. Res., 105, 22255-22267, 2000.

Martin, R. V., Jacob, D. J., Yantosca, R. M., Chin, M., and Ginoux, P.: Global and regional decreases in tropospheric oxidants from photochemical effects of aerosols, J. Geophys. Res., 108, 4097, doi:10.1029/2002JD002622, 2003.

Mishchenko, M. I.: Vector radiative transfer equation for arbitrarily shaped and arbitrarily oriented particles: a microphysical derivation from statistical electromagnetics, Appl. Optics, 41, 71147134, 2002.

Mishchenko, M. I.: Microphysical approach to polarized radiative transfer: extension to the case of an external observation point, Appl. Optics, 42, 4963-4967, 2003.

Mishchenko, M. I. and Travis, L. D.: Light scattering by polydisperse, rotationally symmetric particles: linear polarization, J. Quant. Spectrosc. Ra., 51, 759-778, 1994.

Mishchenko, M. I., Dlugach, J. M., Yanovitskij, E. G., and Zakharova, N. T.: Bidirectional reflectance of flat, optically thick particulate layers: An efficient radiative transfer solution and applications to snow and soil surfaces, J. Quant. Spectrosc. Ra., 63, 409-432, doi:10.1016/S0022-4073(99)00028-X, 1999.

Mishchenko, M., Hovenier, J., and Travis, L.: Light Scattering by non-Spherical Particles, Academic Press, San Diego, 2000.

Mishchenko, M. I., Travis, L. D., and Lacis, A. A.: Scattering, Absorption, and Emission of Light by Small Particles, Cambridge University Press, 2002.
Mishchenko, M. I., Cairns, B., Hansen, J. E., Travis, L. D., Burg, R., Kaufman, Y. J., Martins, J. V., and Shettle, E. P.: Monitoring of aerosol forcing of climate from space: analysis of measurement requirements, J. Quant. Spectrosc. Ra., 8, 149-161, 2004.

Mishchenko, M. I., Cairns, B., Kopp, G., Schueler, C. F., Fafaul, B. A., Hansen, J. E., Hooker, R. J., Itchkawich, T., Maring, H. B., and Travis, L.: Accurate Monitoring of Terrestrial Aerosols and Total Solar Irradiance Introducing the Glory Mission, B. Am. Meteorol. Soc., 88, 677-691, 2007.

Myhre, G., Samset, B. H., Schulz, M., Balkanski, Y., Bauer, S., Berntsen, T. K., Bian, H., Bellouin, N., Chin, M., Diehl, T., Easter, R. C., Feichter, J., Ghan, S. J., Hauglustaine, D., Iversen, T., Kinne, S., Kirkevåg, A., Lamarque, J.-F., Lin, G., Liu, X., Lund, M. T., Luo, G., Ma, X., van Noije, T., Penner, J. E., Rasch, P. J., Ruiz, A., Seland, Ø., Skeie, R. B., Stier, P., Takemura, T., Tsigaridis, K., Wang, P., Wang, Z., Xu, L., Yu, H., Yu, F., Yoon, J.-H., Zhang, K., Zhang, H., and Zhou, C.: Radiative forcing of the direct aerosol effect from AeroCom Phase II simulations, Atmos. Chem. Phys., 13, 1853-1877, doi:10.5194/acp-13-18532013, 2013.

Olivier, J. G. J. and Berdowski, J. J. M.: Global emissions sources and sinks, in: The Climate System, edited by: Berdowski, J., Guicherit, R., and Heij, B. J., 33-78, A. A. Balkema Publishers/Swets \& Zeitlinger Publishers, Lisse, The Netherlands, 2001.

Park, R. J., Jacob, D. J., Chin, M., and Martin, R. V.: Sources of carbonaceous aerosols over the United States and implications for natural visibility, J. Geophys. Res., 108, 4355, doi:10.1029/2002JD003190, 2003.

Park, R. J., Jacob, D. J., Field, B. D., Yantosca, R. M., and Chin, M.: Natural and transboundary pollution influences on sulfate-nitrate-ammonium aerosols in the United States: implications for policy, J. Geophys. Res., 109, D15204, doi:10.1029/2003JD004473, 2004.

Peralta, R. J., Nardell, C., Cairns, B., Russell, E. E., Travis, L. D., Mishchenko, M. I., Fafaul, B. A., and Hooker, R. J.: Aerosol Polarimetry Sensor for the Glory Mission, Proc. SPIE, 6786, 67865L, doi:10.1117/12.783307, 2007.

Price, C. and Rind, D.: A simple lightning parameterization for calculating global lightning distributions, J. Geophys. Res., 97, 9919-9933, 1992.

Remer, L. A., Kaufman, Y. J., Tanre, D., Mattoo, S., Chu, D. A., Martins, J. V., Li, R.-R., Ichoku, C., Levy, R. C., Kleidman, R. G., Eck, T. F., Vermote, E., and Holben, B. N.: The MODIS Aerosol Algorithm, Products, and Validation, J. Atmos. Sci., 62, 947-973, doi:10.1175/JAS3385.1, 2005

Salomonson, V. V., Barnes, W. L., Maymon, P. W., Montgomery, H. E., and Ostrow, H.: MODIS, advanced facility instrument for studies of the Earth as a system, IEEE T. Goesci. Remote, 27, 145-153, 1989.

Sandu, A., Daescu, D. N., Carmichael, G. R., and Chai, T.: Adjoint Sensitivity Analysis of Regional Air Quality Models, J. Comp. Phys., 204, 222-252, 2005.

Schulz, M., Textor, C., Kinne, S., Balkanski, Y., Bauer, S., Berntsen, T., Berglen, T., Boucher, O., Dentener, F., Guibert, S., Isaksen, I. S. A., Iversen, T., Koch, D., Kirkevåg, A., Liu, X., Montanaro, V., Myhre, G., Penner, J. E., Pitari, G., Reddy, S., Seland, $\varnothing$., Stier, P., and Takemura, T.: Radiative forcing by aerosols as derived from the AeroCom present-day and pre-industrial simu- 
lations, Atmos. Chem. Phys., 6, 5225-5246, doi:10.5194/acp-65225-2006, 2006.

Spurr, R. J. D.: VLIDORT: A linearized pseudo-spherical vector discrete ordinate radiative transfer code for forward model and retrieval studies in multilayer multiple scattering media, J. Quant. Spectrosc. Ra., 102, 316-342, doi:10.1016/j.jqsrt.2006.05.005, 2006.

Spurr, R.: LIDORT and VLIDORT: Linearized pseudo-spherical scalar and vector discrete ordinate radiative transfer models for use in remote sensing retrieval problems, Light Scattering Reviews, Vol. 3, edited by: Kokhanovsky, A., Springer, 2008.

Spurr, R., Wang, J., Zeng, J., and Mishchenko, M. I.: Linearized T-matrix and Mie scattering computations, J. Quant. Spectrosc. Ra., 113, 425-439, 2012.

Stier, P., Seinfeld, J. H., Kinne, S., and Boucher, O.: Aerosol absorption and radiative forcing, Atmos. Chem. Phys., 7, 5237-5261, doi:10.5194/acp-7-5237-2007, 2007.

Stier, P., Schutgens, N. A. J., Bellouin, N., Bian, H., Boucher, O., Chin, M., Ghan, S., Huneeus, N., Kinne, S., Lin, G., Ma, X., Myhre, G., Penner, J. E., Randles, C. A., Samset, B., Schulz, M., Takemura, T., Yu, F., Yu, H., and Zhou, C.: Host model uncertainties in aerosol radiative forcing estimates: results from the AeroCom Prescribed intercomparison study, Atmos. Chem. Phys., 13, 3245-3270, doi:10.5194/acp-13-3245-2013, 2013.

Streets, D. G, Zhang, Q., Wang, L., He, K., Hao, J., Wu, Y., Tang, Y., and Carmichael, G. C.: Revisiting China's CO emissions after the Transport and Chemical Evolution over the Pacific (TRACE-P) mission: Synthesis of inventories, atmospheric modeling, and observations, J. Geophys. Res., 111, D14306, doi:10.1029/2006JD007118, 2006.

Tanré, D., Bréon, F. M., Deuzé, J. L., Dubovik, O., Ducos, F., François, P., Goloub, P., Herman, M., Lifermann, A., and Waquet, F.: Remote sensing of aerosols by using polarized, directional and spectral measurements within the A-Train: the PARASOL mission, Atmos. Meas. Tech., 4, 1383-1395, doi:10.5194/amt-4-1383-2011, 2011.

Tegen, I. and Lacis, A. A.: Modeling of particle size distribution and its influence on the radiative properties of mineral dust aerosol, J. Geophys. Res., 101, 19237-19244, 1996.

Textor, C., Schulz, M., Guibert, S., Kinne, S., Balkanski, Y., Bauer, S., Berntsen, T., Berglen, T., Boucher, O., Chin, M., Dentener, F., Diehl, T., Easter, R., Feichter, H., Fillmore, D., Ghan, S., Ginoux, P., Gong, S., Grini, A., Hendricks, J., Horowitz, L., Huang, P., Isaksen, I., Iversen, I., Kloster, S., Koch, D., Kirkevåg, A., Kristjansson, J. E., Krol, M., Lauer, A., Lamarque, J. F., Liu, X., Montanaro, V., Myhre, G., Penner, J., Pitari, G., Reddy, S., Seland, $\varnothing .$, Stier, P., Takemura, T., and Tie, X.: Analysis and quantification of the diversities of aerosol life cycles within AeroCom, Atmos. Chem. Phys., 6, 1777-1813, doi:10.5194/acp-6-1777-2006, 2006. van der Werf, G. R., Randerson, J. T., Giglio, L., Collatz, G. J., Kasibhatla, P. S., and Arellano Jr., A. F.: Interannual variability in global biomass burning emissions from 1997 to 2004, Atmos. Chem. Phys., 6, 3423-3441, doi:10.5194/acp-6-3423-2006, 2006.

Wang, J., Xu, X., Spurr, R., Wang, Y., and Drury, E.: Improved algorithm for MODIS satellite retrievals of aerosol optical thickness over land in dusty atmosphere: Implications for air quality monitoring in China, Rem. Sens. Environ., 114, 2575-2583, 2010.

Wang, J., Xu, X., Henze, D. K., Zeng, J., Ji, Q., Tsay, S.-C., and Huang, J.: Top-down estimate of dust emissions through integration of MODIS and MISR aerosol retrievals with the GEOS-Chem adjoint model, Geophys. Res. Lett., 39, L08802, doi:10.1029/2012GL051136, 2012.

Wang, Y., Jacob, D. J., and Logan, J. A.: Global simulation of tropospheric $\mathrm{O}_{3}-\mathrm{NO}_{\mathrm{x}}$-hydrocarbon chemistry, 1. Model formulation, J. Geophys. Res., 103, 10713-10726, 1998.

Wesely, M. L.: Parameterization of surface resistance to gaseous dry deposition in regional-scale numerical models, Atmos. Environ. 23, 1293-1304, 1989.

Yevich, R. and Logan, J. A.: An assesment of biofuel use and burning of agricultural waste in the developing world, Global Biogeochem. Cy., 17, 1095, doi:10.1029/2002GB001952, 2003.

Yu, H. B., Remer, L. A., Chin, M., Bian, H. S., Tan, Q., Yuan, T. L., and Zhang, Y.: Aerosols from Overseas Rival Domestic Emissions over North America, Science, 337, 566-569, 2012.

Yu, H., Chin, M., West, J. J., Atherton, C. S., Bellouin, N., Bergmann, D., Bey, I., Bian, H., Diehl, T., Forberth, G., Hess, P., Schulz, M., Shindell, D., Takemura, T., and Tan, Q.: A multimodel assessment of the influence of regional anthropogenic emission reductions on aerosol direct radiative forcing and the role of intercontinental transport, J. Geophys. Res., 118, D018148, doi:10.1029/2012JD018148, 2013.

Zaneveld, J. R. V., Twardowski, M. J., Barnard, A., and Lewis, M. R.: Introduction to radiative transfer, in: Remote sensing of Coastal Aquatic Environments, Remote Sensing and Digital Image Processing, Vol. 7, edited by: Miller, R. L., del Castillo, C. E., and McKee, B. A., Springer, Dordrecht, 2005.

Zhang, J. L., Reid, J. S., Westphal, D. L., Baker, N. L., and Hyer, E. J.: A system for operational aerosol optical depth data assimilation over global oceans, J. Geophys. Res.-Atmos., 113, D10208, doi:10.1029/2007JD009065, 2008. 